\title{
Somatic and visceral afferents to the 'vasodepressor region' of the caudal midline medulla in the rat
}

\author{
Jason R. Potas, ${ }^{1}$ Kevin A. Keay, ${ }^{1,2}$ Luke A. Henderson ${ }^{1}$ and Richard Bandler ${ }^{1,2}$ \\ ${ }^{1}$ Department of Anatomy and Histology, The University of Sydney, NSW, Australia 2006 \\ ${ }^{2}$ Pain Management \& Research Centre, The University of Sydney at Royal North Shore Hospital, NSW, Australia
}

Keywords: haemorrhage, nucleus of the solitary tract, pain, raphe, shock, spinal cord, spinal trigeminal nucleus, SpV

\begin{abstract}
Previous research has found that the integrity of a restricted region of the caudal midline medulla (including caudal portions of nucleus raphé obscurus and nucleus raphé pallidus) was critical for vasodepression (hypotension, bradycardia, decreased cardiac contractility) evoked either by haemorrhage or deep pain. In this anatomical tracing study we found that the vasodepressor part of the caudal midline medulla (CMM) receives inputs arising from spinal cord, spinal trigeminal nucleus (SpV) and nucleus of the solitary tract (NTS). Specifically: (i) a spinal-CMM projection arises from neurons of the deep dorsal horn, medial ventral horn and lamina $\mathrm{X}$ at all spinal segmental levels, with approximately $60 \%$ of the projection originating from the upper cervical spinal cord (C1-C4); (ii) a SpV-CMM projection arises primarily from neurons at the transition between subnucleus caudalis and subnucleus interpolaris; (iii) a NTS-CMM projection arises primarily from neurons in ventrolateral and medial subnuclei. In combination, the specific spinal, SpV and NTS regions which project to the CMM receive the complete range of somatic and visceral afferents known to trigger vasodepression. The role(s) of each specific projection is discussed.
\end{abstract}

\section{Introduction}

Neurons of the caudal midline medulla (CMM), including the caudal portions of the nucleus raphé obscurus and nucleus raphé pallidus are known to influence sympathetic activity and to mediate changes in arterial pressure and heart rate (Gilbey et al., 1981; Pilowsky et al., 1986; Minson et al., 1987; Yen \& Hwang, 1989; Yen et al., 1991; Morrison, 1993; D’ Amico et al., 1996; Faria et al., 1996; Almada et al., 1997). Recently, several laboratories reported that excitation of neurons in a discrete part of the CMM evoked a strong vasodepression response. Specifically in halothane and barbiturate anaesthetized rats, or barbiturate-anaesthetized rabbits, small microinjections (10-50 nL) of excitatory amino acids into the CMM, between the level of the obex to $+1.5 \mathrm{~mm}$ above the obex, evoke sympathoinhibition, hypotension and bradycardia (Coleman \& Dampney, 1995; Coleman \& Dampney, 1998; Henderson et al., 1998b; Heslop et al., 2002; Verberne et al., 1999). Further, it was found in both halothane and urethane anaesthetized rats, that this discrete CMM region is part of the neural network which mediates the hypotensive (phase II/decompensatory) response to progressive blood loss (Henderson et al., 1998a, 2000, 2002; Heslop et al., 2002). Specifically, microinjection of local anaesthetic (lignocaine) or a synaptic blocker (cobalt chloride) into the vasodepressor part of the CMM either blocks (lignocaine) or delays and attenuates (cobalt chloride) the hypotension and bradycardia triggered by a hypotensive haemorrhage (Henderson et al., 1998a, 2000, 2002; Heslop et al., 2002). Interestingly the same manipulations do not alter resting arterial pressure and heart rate; nor do they affect the hypotension and bradycardia evoked by excitation of 5-HT3 cardiopulmonary vagal afferents or the bradycardia triggered by

Correspondence: Dr Kevin A. Keay, ${ }^{1}$ Department of Anatomy and Histology, as above. E-mail: keay@anatomy.usyd.edu.au

Received 1 November 2002, revised 27 December 2002, accepted 7 January 2003 baroreceptor loading (Coleman \& Dampney, 1998; Henderson et al., 2000). Such data suggest that the CMM 'vasodepressor' region plays no significant role in 'homeostatic' cardiovascular functions, although clearly its integrity is critical in evoking the decompensatory (phase II) response to progressive blood loss (for further discussion of this issue see Henderson et al., 2000).

It has been thought that the decompensatory/phase II response to severe haemorrhage is triggered by signals arising in vagal (cardiac) afferents from right atrial and ventricular mechanoreceptors activated as a result of poor cardiac (diastolic) filling (Oberg \& Thoren, 1970; Oberg \& Thoren, 1972; Oberg \& Thoren, 1973). However, it has been suggested also that nociceptive signals originating from ischaemic tissues may play an important role, i.e. if blood loss continues the combination of increased sympathetic (vasoconstrictor) drive to maintain arterial pressure (compensatory/phase I response) and falling cardiac output will produce severe ischaemia in many visceral and skeletal muscle beds (Evans \& Ludbrook, 1991; Schadt \& Ludbrook, 1991; Fitzpatrick et al., 1993; Ludbrook, 1993; Evans et al., 1994). With respect to the CMM and the role of nociceptive afferents triggering the decompensatory response, Johansson observed 40 years ago (Johansson, 1962) that electrolytic lesions of the midline medulla (including the CMM 'vasodepressor' region) blocked hypotension and bradycardia evoked by electrical stimulation of 'nociceptive' muscle afferents (i.e. A- $\delta$ and C-fibres in the sciatic nerve of the cat). The same midline medullary lesions, however, had no effect on the hypotension and bradycardia evoked by electrical stimulation of the vagus.

A previous neuroanatomical tracing study by Henderson et al. (1998b) found that the vasodepressor part of the CMM receives a significant projection from the ventrolateral column of the periaqueductal grey (vlPAG). The vlPAG itself receives direct afferents from spinal cord laminae in which primary afferents from deep tissues (muscles, joints, viscera) terminate (Keay et al., 1997; Clement et al., 
2000); and subnuclei of the nucleus of the solitary tract in which vagal and spinal afferents terminate (Herbert \& Saper, 1992). Further, using immediate-early gene expression as a marker of neuronal activation, it has been found that vlPAG neurons are activated by noxious stimulation of muscles, joints or viscera (Keay \& Bandler, 1993; Keay et al., 1994; Clement et al., 1996; Keay \& Bandler, 1998; Keay et al., 2002) or by a hypotensive haemorrhage (Keay et al., 2002). Recently we, and others reported that neural blockade of the vlPAG (lignocaine) or injection into the vIPAG of opioid antagonists, delayed and attenuated the decompensatory response to haemorrhage (Cavun \& Millington, 2001; Cavun et al., 2001; Ip et al., 2002). Such data suggest that haemorrhage-evoked hypotension and bradycardia may be triggered by a descending projection from the vlPAG to the CMM. However, the possibility that CMM neurons may be activated also by more direct somatic and visceral afferent pathways has yet to be evaluated. The aim of the present anatomical tracing study, using the retrograde transport of cholera-toxin subunit $\mathrm{B}$, was to determine whether the CMM 'vasodepressor' region receives afferents of spinal, spinal trigeminal $(\mathrm{SpV})$ or solitary tract nucleus (NTS) origins.

\section{Methods}

All experiments were carried out following the guidelines of the NHMRC 'Code of Practice for the Care and Use of Animals in Research in Australia' and with the approval from the University of Sydney Animal Care Ethics Committee.

Retrograde tracer injection was made in 20 male Sprague-Dawley rats $(350-450 \mathrm{~g})$. Each animal was anaesthetized with an $(0.15 \mathrm{~mL})$ intramuscular injection of ketamine $(100 \mathrm{mg} / \mathrm{kg})$, xylazine $(4 \mathrm{mg} / \mathrm{kg})$, and acepromazine $(0.5 \mathrm{mg} / \mathrm{kg})$. Each rat was placed (flat skull position) in a stereotaxic holder, and a small midline bone flap was removed exposing the caudal portion of the cerebellum and the dorsal surface of the medulla. A micropipette containing cholera toxin $\beta$-subunit $(\mathrm{CTb})$ (List Biologicals, low salt), was lowered at $10^{\circ}$ (caudo-rostral) angle onto the obex. The micropipette was then lowered $+1.5 \mathrm{~mm}$ rostral, and $1.5-2.5 \mathrm{~mm}$ below the obex into the caudal midline medulla. CTb was deposited by iontophoresis using $2-15 \mu \mathrm{A}$ pulses ( 7 second duty cycle) over 15-30 min. The micropipette was then removed and the wound closed. Animals were then given $2 \mathrm{~mL}$ saline (i.p) and analgesics (buprenorphine, $0.075 \mathrm{mg} / \mathrm{kg}$ ). Each rat was then placed in a recovery box $\left(37-38^{\circ} \mathrm{C}\right)$ for $3-6 \mathrm{~h}$ after which it was returned to its home-cage. During the next 2-4 days the mobility, activity level, eating, drinking and grooming of each rat was closely observed.

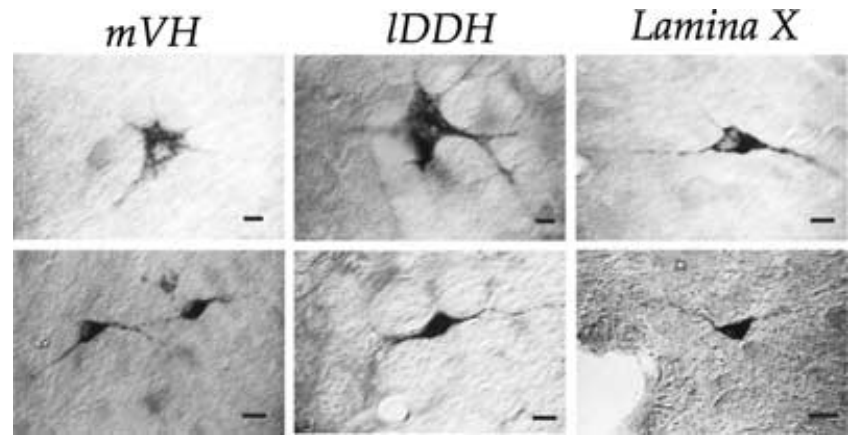

FIG. 1. Photomicrographs showing spinal cord neurons retrogradely labelled with cholera-toxin subunit B and visualized with Nickel-enhanced diaminobenzidine following injections into the vasodepressor region of the caudal midline medulla. The images show labelled neurons from the medial ventral horn $(\mathrm{mVH})$, the lateral deep dorsal horn (1DDH) and lamina $\mathrm{X}$. The scale bar in the bottom right of each image shows $20 \mu \mathrm{m}$.
Ten days later, each animal was deeply anaesthetized (sodium pentabarbitone, $60 \mathrm{mg} / \mathrm{kg}$ ) and transcardially perfused with heparinized saline $(500 \mathrm{~mL} ; 0.9 \%$; $\mathrm{pH} 7.4$; room temperature) followed by $4 \%$ paraformaldehyde in a borate buffer $\left(500 \mathrm{~mL} ; \mathrm{pH} 9.4 ; 4{ }^{\circ} \mathrm{C}\right)$. The brain and spinal cord were removed and post fixed (1-2h), before being placed in $30 \%$ sucrose $\left(0.1 \mathrm{M}\right.$ phosphate buffer; $\left.\mathrm{pH} 7.4 ; 4{ }^{\circ} \mathrm{C}\right)$ for a minimum of 2 days.

\section{Retrograde label in spinal cord}

For 13 brains, coronal sections of a medullary block, containing the $\mathrm{CMM}$ injection site, were cut at $60 \mu \mathrm{m}$. For each medulla in which the injection site was within the vasodpressor part of the CMM (see below), the spinal cord was divided into eight spinal segmental regions: C1, C2-C4, C5-C8, T1-T5, T6-T10, T11-L2, L3-L6, and $\mathrm{S} 1-\mathrm{S} 3$, and coronal sections of each segmental region were cut at $40 \mu \mathrm{m}$.

\section{Retrograde label in SpV and NTS}

For seven other brains the medulla was sectioned at $50 \mu \mathrm{m}$ and both the injection sites and the location of retrogradely labelled neurons within the medulla were examined.

All sections were washed, free-floating, in $50 \%$ ethanol followed by $3 \%$ hydrogen peroxide in $50 \%$ ethanol. Sections were rinsed in $0.1 \mathrm{M}$ phosphate buffer (PB) solution ( $\mathrm{pH} 7.4)$ for $30 \mathrm{~min}$, followed by blocking in normal horse serum (NHS; $10 \%$ in PB; 30 min). Sections were incubated overnight in goat anticholeragenoid (List Biologicals; $1: 15000-1: 30000$ in phosphate buffered horse serum $(\mathrm{PBH} ; 0.1 \%$ bovine serum albumin, $2 \%$ NHS in $0.1 \mathrm{M} \mathrm{PB}, \mathrm{pH} 7.4$; room temperature). Sections were washed in $\mathrm{PB}$ and incubated for $2 \mathrm{~h}$ in biotinylated

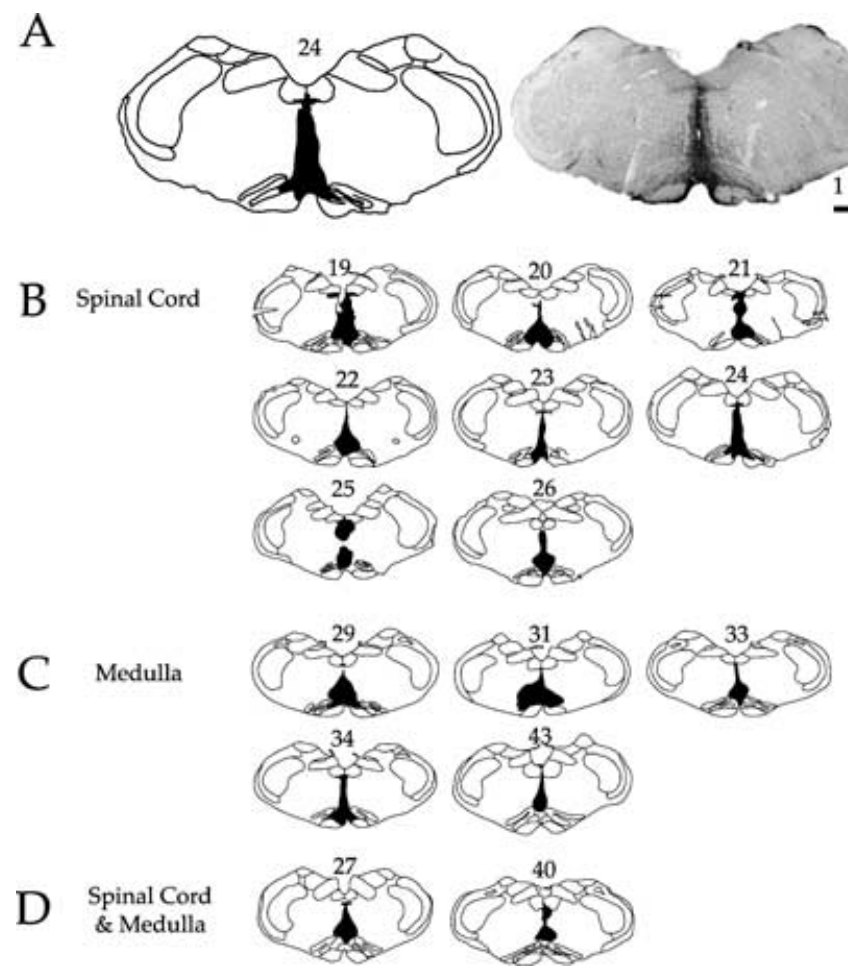

FIG. 2. (A) Camera-lucida reconstruction (left) and photomicrograph (right) of a coronal section of the medulla illustrating the centre of the CTb injection into the vasodepressor region of the CMM from animal 24. The injection site was visualized with nickel-enhanced diaminobenzidine (see Methods). (B-D) Camera-lucida reconstructions of the injection sites of the 15 animals from which data are reported. Note that the injections in rats 27 and 40 (row D) show no spread into the inferior olivary nuclei located below. 
A

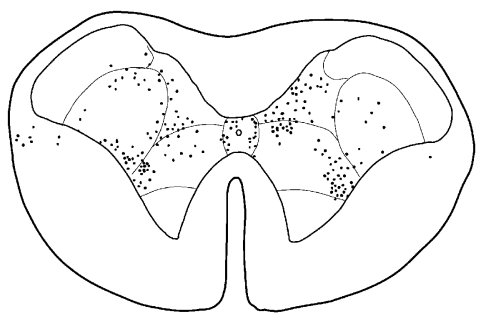

B
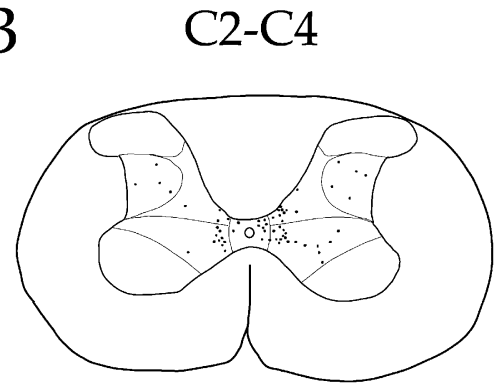

C

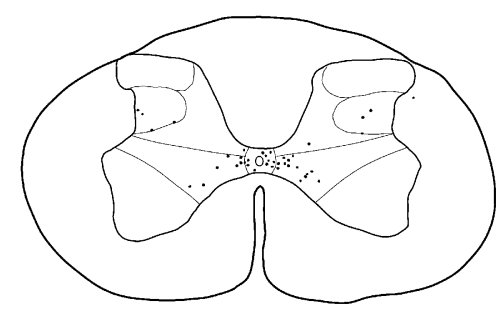

C5-C8

D

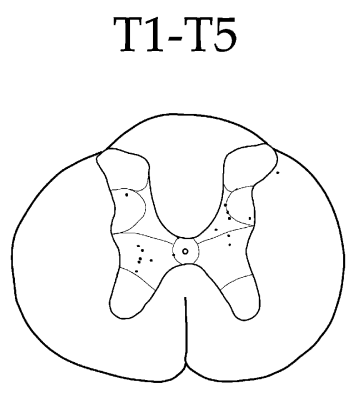

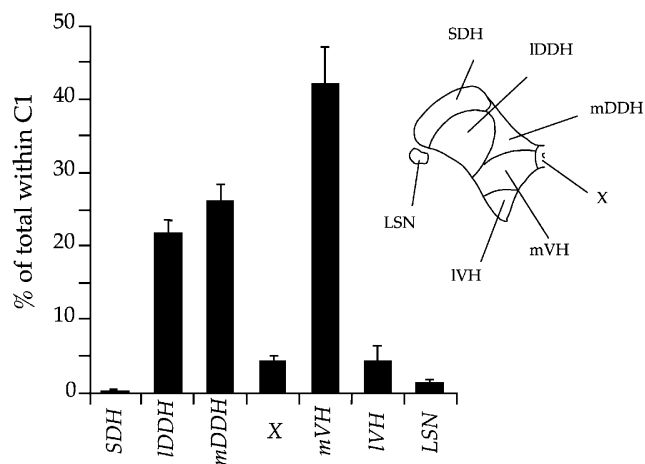
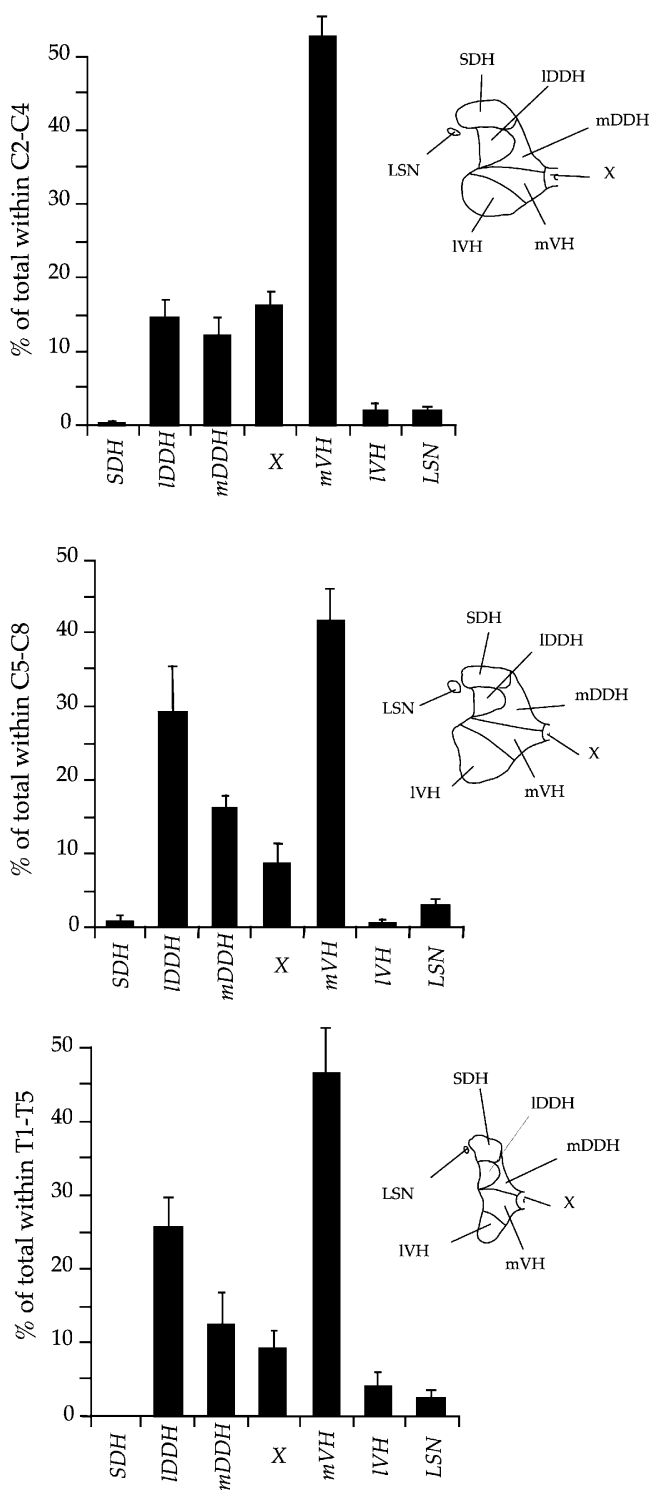

FIG. 3. Left-hand column, standard coronal sections of each spinal segmental region analysed: (A) C1; (B) C2-C4; (C) C5-C8; (D) T1-T5; (E) T6-T10; (F) T11-L2; (G) L3-L6 and (H) S1-S3 (see next page). The retrogradely labelled neurons from $10(40 \mu \mathrm{m})$ sections are shown on each section (black dots) for each spinal segmental region (data from rat 24). Right-hand column, histograms illustrating the laminar locations of retrogradely labelled neurons within each spinal segmental region. The data are expressed as a percentage $( \pm \mathrm{SEM})$ of the total number of neurons within that spinal segmental region for all animals analysed. The laminar regions are shown in the adjacent schematic diagram of a coronal section of the cord.

antigoat IgG (Vector; $1: 200$ in PBH). Sections were washed again for 30 min in PB and incubated in Extr-Avidin Peroxidase (Sigma; $1: 1000$ in PBH; 2.5 h). Following a final wash in PB, the bound antibody was visualized with diaminobenzadine (DAB) as the chromagen using the glucose oxidase technique (see (Keay et al., 1997) for details).
Sections were then mounted onto gelatinized slides, dried overnight, dehydrated through graded alcohols and coverslipped with DPX mounting medium (Ajax Chemicals).

Sections were observed under the light microscope and injection sites were reconstructed using a camera-lucida attachment. Cells were 

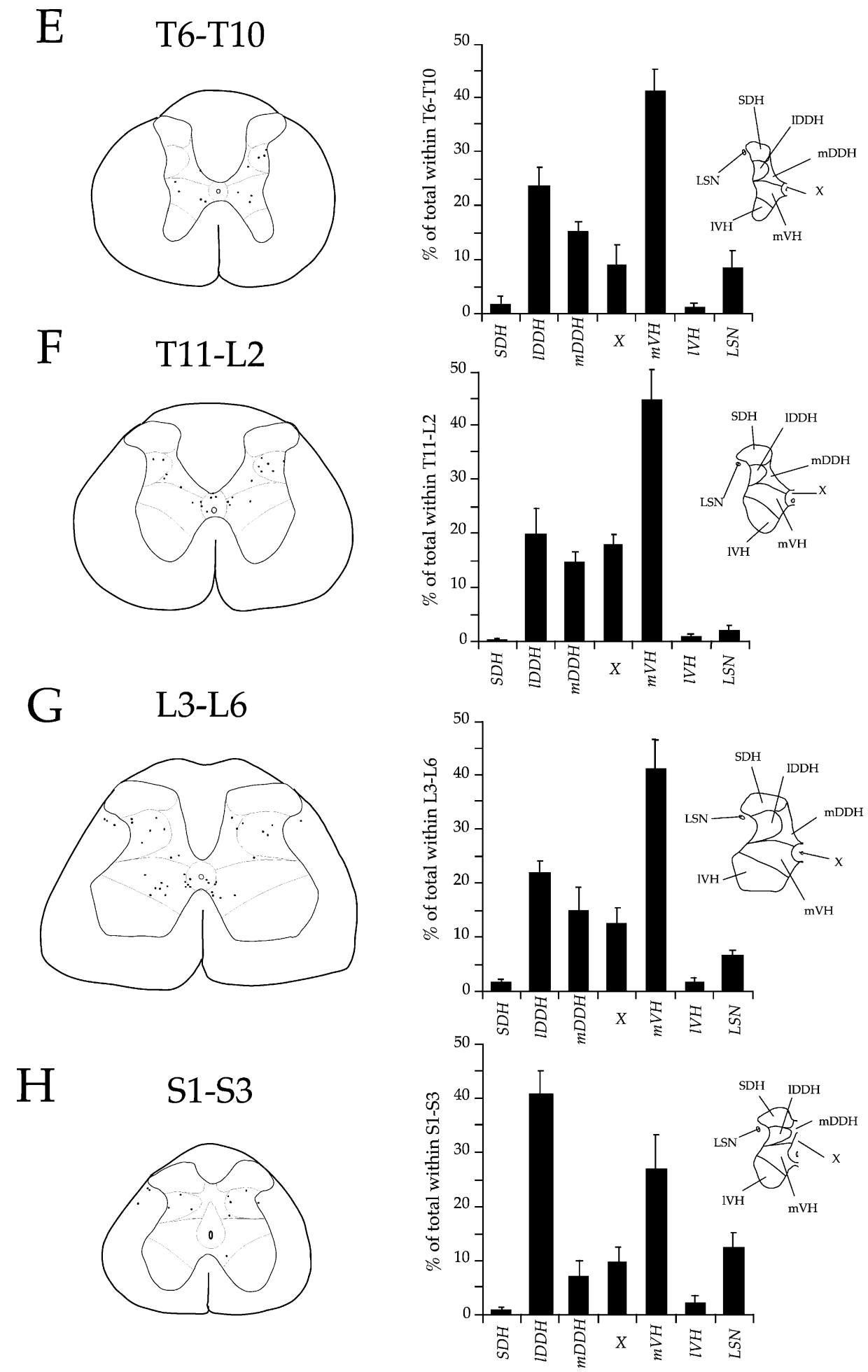

FIG. 3. continued

considered to be retrogradely labelled if the $\mathrm{CTb}$-immunoreactivity (IR) could be clearly differentiated from background staining at $\times 100$, and the soma contained a granular brown reaction product visible at $\times 200$ (see Fig. 1). To plot the location of retrogradely labelled neurons in the spinal cord, representative ('standard') sections at each of the 8 spinal segmental regions $(\mathrm{C} 1, \mathrm{C} 2-\mathrm{C} 4, \mathrm{C} 5-\mathrm{C} 8, \mathrm{~T} 1-\mathrm{T} 5, \mathrm{~T} 6-\mathrm{T} 10$, T11-L2, L3-L6, S1-S3) were drawn using the camera-lucida attachment. For numerical analysis the CTb-IR cells on 10 randomly selected sections, at each segmental level, were plotted onto the 'standard sections'. The mean number of CTb-IR (labelled) cells per section $(40 \mu \mathrm{m})$ was then calculated for each spinal segmental region.

For each spinal segmental region the boundaries of the superficial dorsal horn (SDH), lateral deep dorsal horn (IDDH), medial deep dorsal horn $(\mathrm{mDDH})$, lamina $\mathrm{X}$, medial ventral horn $(\mathrm{mVH})$, lateral ventral horn (IVH), and lateral spinal nucleus (LSN) were delineated using cytoarchitectonic criteria based on Nissl stained spinal cord 

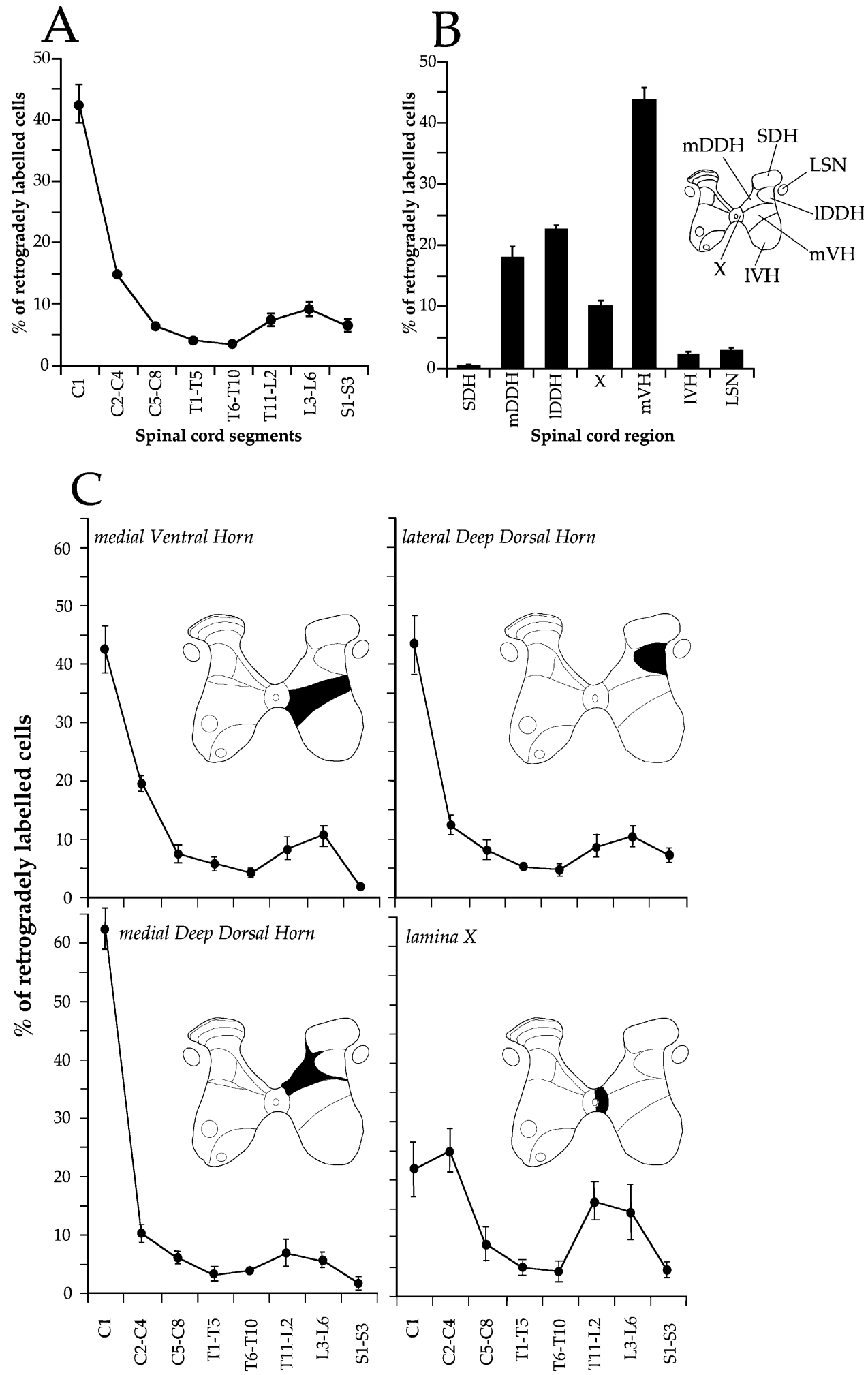

\section{Spinal cord segments}

FIG. 4. (A) Graph illustrating the distribution of retrogradely labelled neurons within each of the eight spinal segmental regions analysed. The data are expressed as a percentage $( \pm$ SEM) of the total number of neurons labelled in each animal. (B) Histogram illustrating the distribution of retrogradely labelled neurons within each laminar region. The data are expressed as a percentage $( \pm$ SEM $)$ of the total number of neurons labelled in each animal. The laminar regions analysed are shown in the schematic diagram of a coronal section of the cord (above right). (C) Graphs illustrating the distribution of retrogradely labelled neurons within: (i) the medial ventral horn; (ii) the lateral deep dorsal horn; (iii) the medial deep dorsal horn; and (iv) lamina X; of the eight spinal segmental regions analysed. The data are expressed as a percentage $( \pm \mathrm{SEM})$ of the total number of neurons labelled in each laminar region. The laminar region analysed is shown in the schematic diagram of a coronal section of the cord above each graph. 
sections. These boundaries followed the schema proposed by Molander and Grant (Molander \& Grant, 1995). The SDH included laminae I, II, III, and lateral part of lamina IV. The deep dorsal horn (lamina V) was subdivided into two regions, a lateral (IDDH) and medial (mDDH) sector. The lateral deep dorsal horn contained only the 'reticular' cells of lamina $\mathrm{V}$. The medial deep dorsal horn contained neurons of lamina V, medial lamina IV and lamina VI of the C4-T8, and L3-L6 segments. The ventral horn was divided into medial and lateral sectors. The medial ventral horn $(\mathrm{mVH})$ contained primarily neurons of lamina VII, with some lamina VIII neurons. The lateral ventral horn (IVH) contained the remaining lamina VIII neurons and the motor neurons of lamina IX.

To determine the location of retrogradely labelled neurons in both the NTS and spinal trigeminal nucleus (SpV), seven sections (spaced $\sim 500 \mu \mathrm{m}$ apart) from the $\mathrm{C} 1$ spinal segment through to the level $1.5 \mathrm{~mm}$ rostral to the obex were selected. Each section was drawn and the labelled cells plotted onto these sections using the camera-lucida attachment. The NTS was subdivided in accordance with the schema of Herbert and Saper (Herbert et al., 1990; Herbert \& Saper, 1992). The $\mathrm{SpV}$ regions were subdivided on the basis of a number of recent studies (Hathaway et al., 1995; Jacquin et al., 1983; Jacquin et al., 1986; Imbe et al., 1999; Zhou et al., 1999; Imbe et al., 2001)

\section{Results}

The data of 15 rats in which the $\mathrm{CTb}$ injections were restricted to the vasodepressor part of the CMM were analysed in detail. For eight rats (numbers 19-26) retrograde label in the spinal cord was analysed. For 5 rats $(29,31,33,34$ and 43) retrograde label in the medulla (NTS, $\mathrm{SpV}$ ) was evaluated, and in the remaining two rats (27 and 40) retrograde label in both spinal cord and medulla was analysed. Camera-lucida reconstructions of each of the centres of the injection sites are shown in Fig. 2. The patterns of retrograde label in both spinal cord and medulla for two animals in which there was no appreciable spread of CTb into the underlying inferior olives (injections 27 and 40) were compared with those of the other 13 animals.

\section{Spinal cord}

$\mathrm{CTb}$-IR neurons were distributed bilaterally, at each of the spinal segmental regions investigated (see Fig. 3). However, there were striking differences in the numbers of labelled cells in each of the

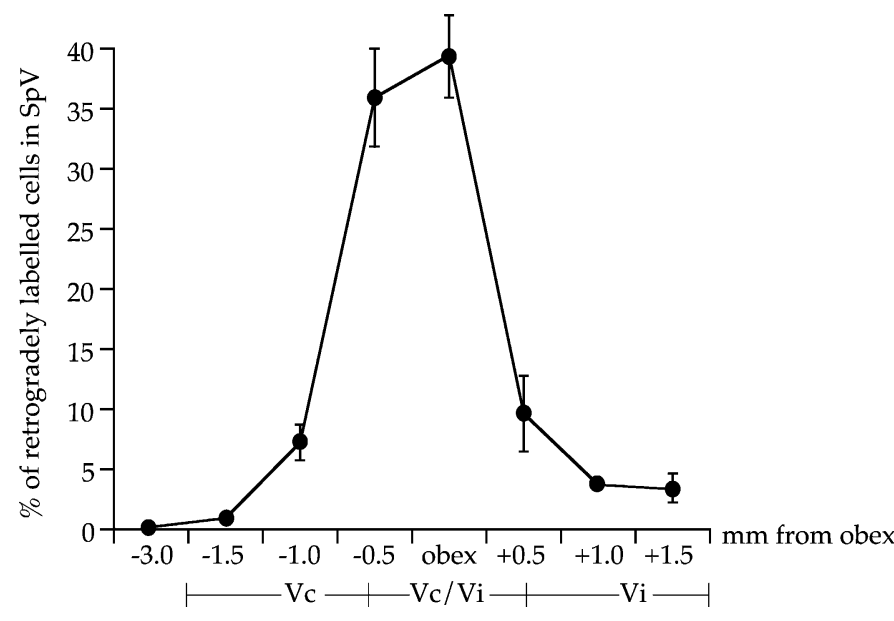

FIG. 5. Graph illustrating the distribution of retrogradely labelled neurons within the spinal nucleus of the trigeminal $(\mathrm{SpV})$ at each of the eight medullary sections $(500 \mu \mathrm{m}$ apart) analysed. The rostro-caudal location of the sections are defined according to distance $(\mathrm{mm})$ from obex. The data are expressed as a percentage $( \pm \mathrm{SEM})$ of the total number of neurons labelled in the $\mathrm{SpV}$ of each animal.

8 spinal segmental regions (Figs 3 and 4A, Table 1). Approximately $60 \%$ of the labelled cells were found within the upper cervical spinal segments (C1-C4), of which at least $40 \%$ were contained solely within the $\mathrm{C} 1$ segment. A similar distribution of retrograde label was found for the two CMM injections sites without involvement of the inferior olive (Table 1). Each of the 7 remaining spinal segmental regions (C5 and below) contained between 4 and 10\% (mean values) of the total number of CTb-IR neurons.

At each spinal segmental region labelled neurons were located only within specific laminae (see Figs 3 and 4B). The SDH was notable by a near total absence of CTb-IR neurons. The greatest number of retrogradely labelled spinal neurons were found within the medial half of the ventral horn $(\mathrm{mVH}=44 \pm 2 \%)$. A further $42 \%$ of all labelled neurons were located within the deep dorsal horn, $23 \pm 1 \%$ laterally (lDDH); $19 \pm 2 \%$ medially (mDDH). However, it is important to note that the number of labelled neurons within the mDDH was reduced by half for the two rats in which the CMM injections sites did not infringe upon the inferior olives. Lamina X, surrounding the central canal contained $10 \%$ of all labelled neurons. Smaller numbers of

TABLE 1. Numbers of retrogradely labelled (CTb-IR) neurons in 10 randomly selected coronal sections at each spinal cord segmental region

\begin{tabular}{|c|c|c|c|c|c|c|c|c|c|}
\hline \multirow[b]{2}{*}{ Animal } & \multicolumn{9}{|c|}{ Numbers of retrogradely labelled (CTb-IR) neurons (also as percentages of all labelled cells found in each region) } \\
\hline & $\mathrm{C} 1$ & $\mathrm{C} 2-\mathrm{C} 4$ & $\mathrm{C} 5-\mathrm{C} 8$ & T1-T5 & T6-T10 & T11-L2 & L3-L6 & $\mathrm{S} 1-\mathrm{S} 3$ & Total \\
\hline 19 & $178(32.9 \%)$ & $81(14.9 \%)$ & $44(8.1 \%)$ & $36(6.7 \%)$ & $37(6.8 \%)$ & $49(9.1 \%)$ & $86(15.9 \%)$ & $30(5.5 \%)$ & 541 \\
\hline 20 & - & 36 & 6 & 9 & 7 & 5 & 21 & 3 & - \\
\hline 21 & $287(53.9 \%)$ & $82(15.4 \%)$ & $34(6.4 \%)$ & $24(4.5 \%)$ & $16(3.0 \%)$ & $29(5.5 \%)$ & $42(7.9 \%)$ & $18(3.4 \%)$ & 532 \\
\hline 22 & $140(42.0 \%)$ & $50(15.0 \%)$ & $21(6.3 \%)$ & $16(4.8 \%)$ & $18(5.4 \%)$ & $34(10.2 \%)$ & $36(10.8 \%)$ & $18(5.4 \%)$ & 333 \\
\hline 23 & $113(47.9 \%)$ & $40(16.9 \%)$ & $18(7.6 \%)$ & $11(4.7 \%)$ & $8(3.4 \%)$ & $20(8.5 \%)$ & $19(8.1 \%)$ & $7(3.0 \%)$ & 236 \\
\hline 24 & $210(50.8 \%)$ & $60(14.5 \%)$ & $41(9.9 \%)$ & $17(4.1 \%)$ & $12(2.9 \%)$ & $23(5.6 \%)$ & $40(9.7 \%)$ & $10(2.4 \%)$ & 413 \\
\hline 25 & - & 82 & 46 & 21 & 33 & 42 & 47 & 31 & - \\
\hline 26 & $100(41.1 \%)$ & $48(19.8 \%)$ & $14(5.8 \%)$ & $11(4.5 \%)$ & $10(4.1 \%)$ & $29(11.9 \%)$ & $24(9.9 \%)$ & $7(2.9 \%)$ & 243 \\
\hline 27 & $141(42.3 \%)$ & $63(18.9 \%)$ & $22(6.6 \%)$ & $20(6.0 \%)$ & $25(7.5 \%)$ & $26(7.8 \%)$ & $25(7.5 \%)$ & $11(3.3 \%)$ & 333 \\
\hline 40 & $298(44.3 \%)$ & $104(15.5 \%)$ & $75(11.1 \%)$ & $49(7.3 \%)$ & $30(4.5 \%)$ & $55(8.2 \%)$ & $46(6.8 \%)$ & $16(2.4 \%)$ & 673 \\
\hline
\end{tabular}

FIG. 6. Left-hand column, standard coronal sections of each of the eight coronal sections of medulla in which SpV label was analysed ( $+1.5 \mathrm{~mm}$ to $-3.0 \mathrm{~mm}$ relative to obex). Sections A-C correspond to the subnucleus interpolaris ( $\mathrm{SpVi}$ ), sections $\mathrm{C}$ and D correspond to the 'transitional region' $\mathrm{SpVi} / \mathrm{SpVc}$, and sections $\mathrm{E}-\mathrm{G}$ (see next pages) correspond to the subnucleus caudalis $(\mathrm{SpVc})$. The retrogradely labelled neurons from one side of a single section $(50 \mu \mathrm{m})$ are shown as black dots (data from rat 43). Right-hand column, histograms illustrating: (i) the dorso-ventral, and (ii) the medio-lateral locations of retrogradely labelled neurons at each of the medullary levels. The data are expressed as a percentage $( \pm$ SEM) of the total number of neurons within that medullary rostrocaudal level for all animals analysed. The dorso-ventral and medio-lateral regions are shown schematically in the figure. 
A

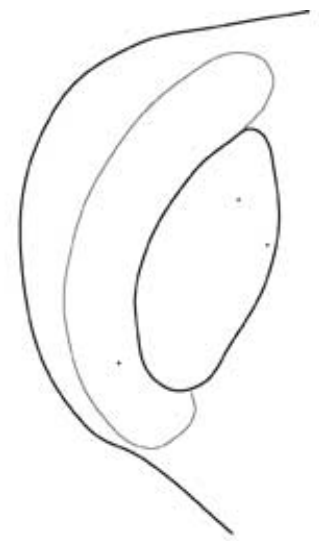

B

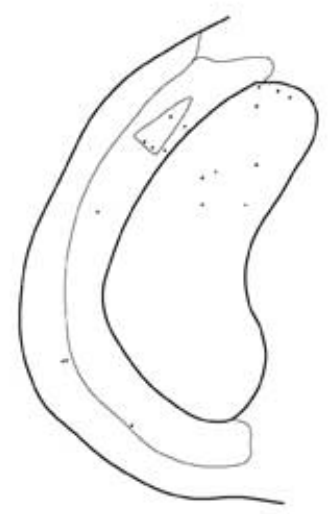

$\complement$

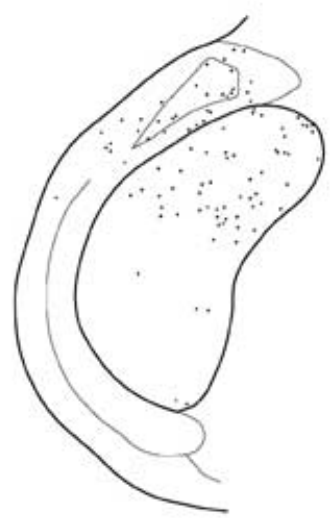

$\mathrm{D}$

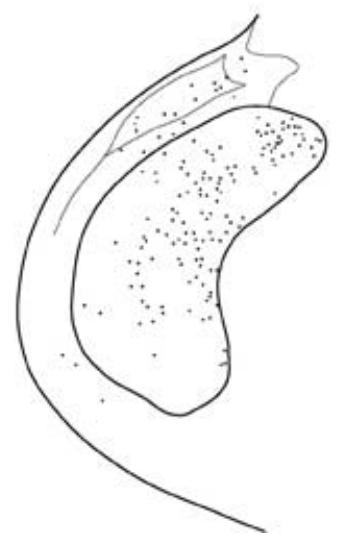

$+1.5$
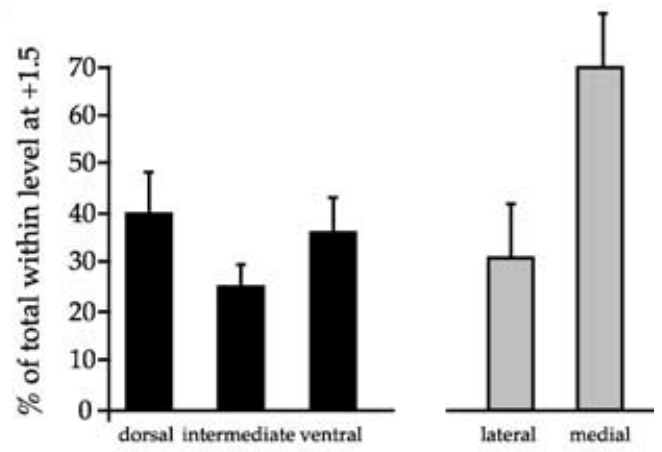

$+1.0$
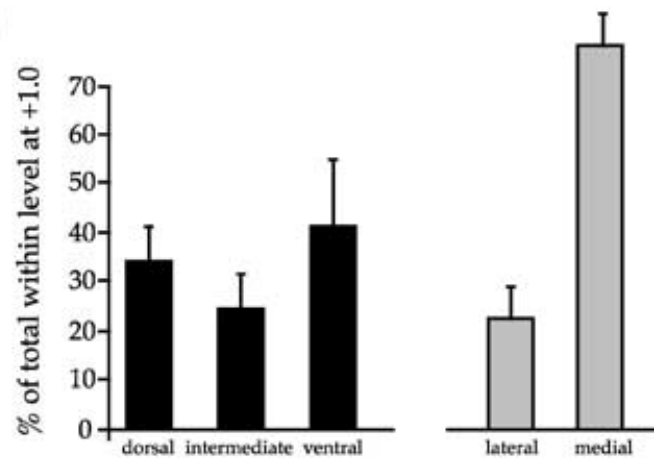

$+0.5$
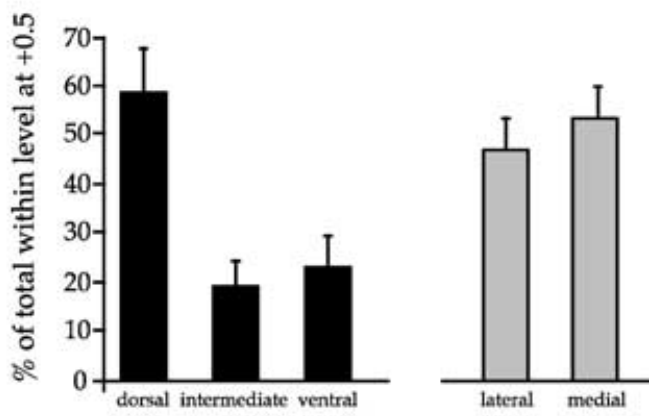

obex

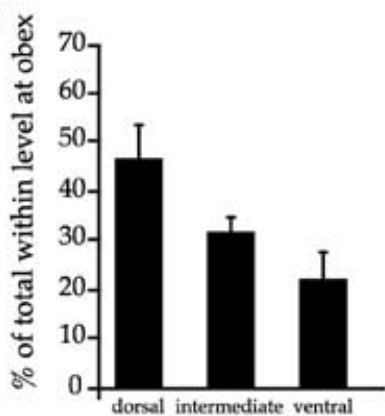


1142 J. R. Potas et al.

E

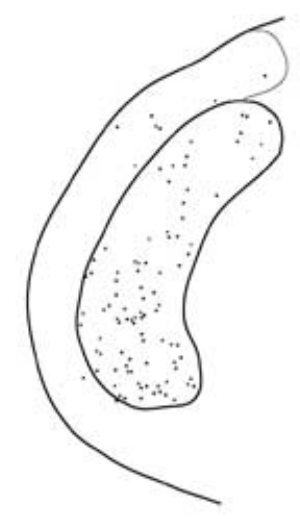

F

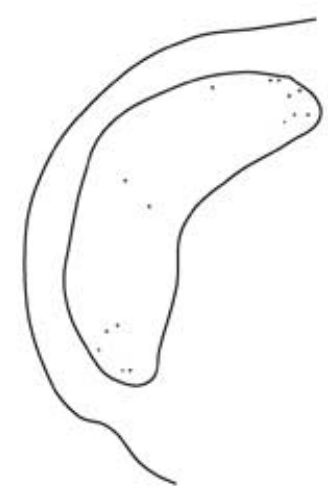

$-1.0$

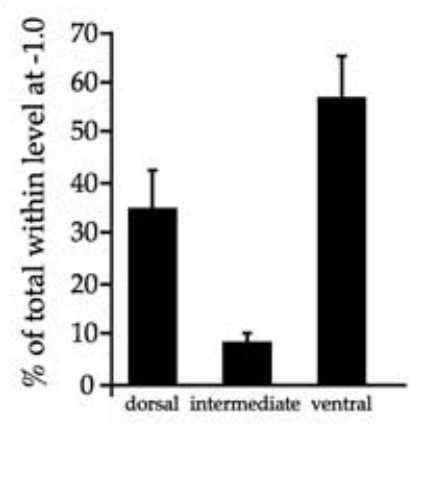

$-1.5$

G

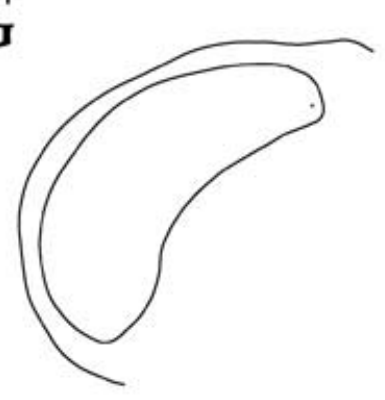

$-0.5$

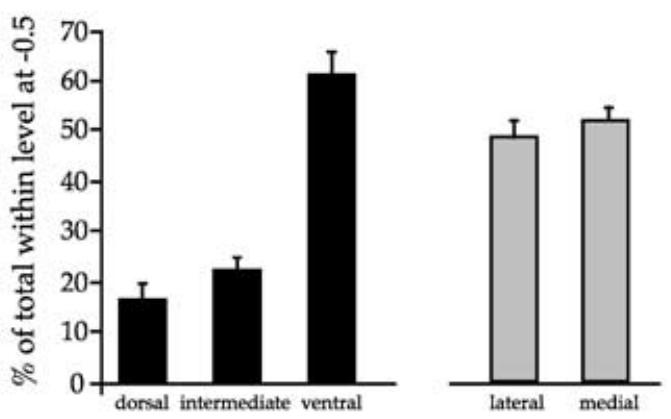

$\mathrm{H}$

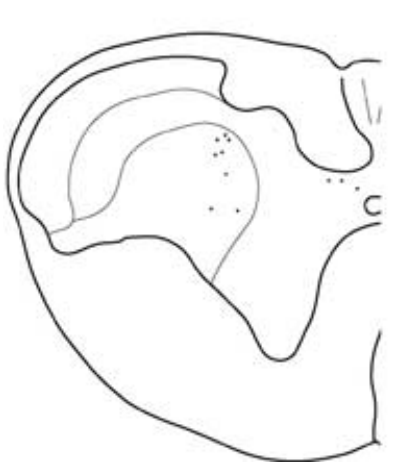

$-3.0$

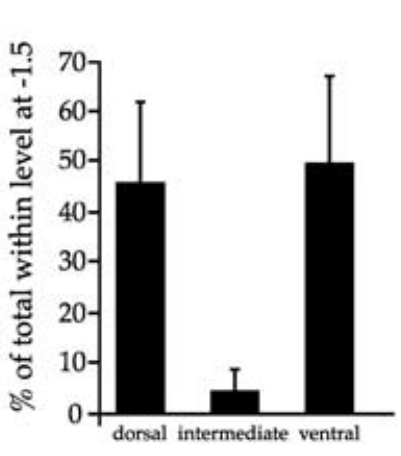

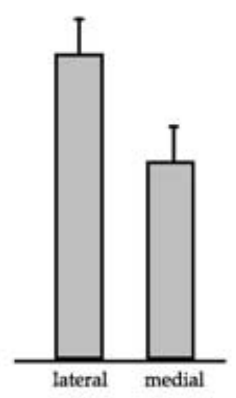

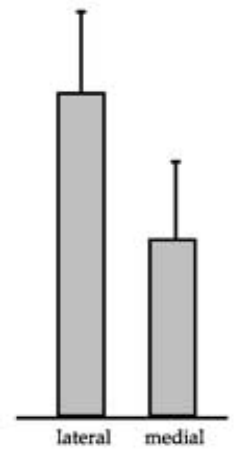

FIG. 6. continued

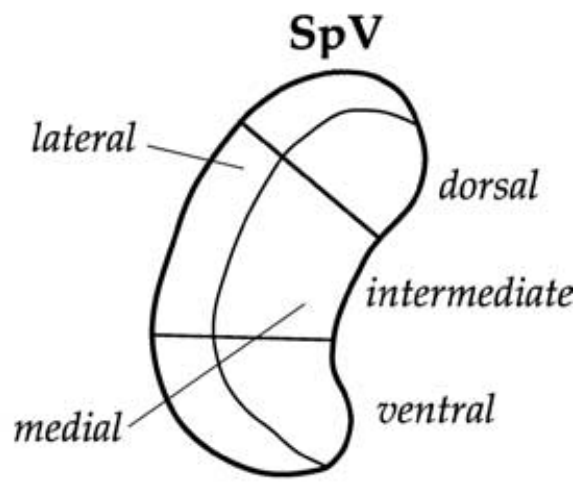


TABLE 2. Numbers of retrogradely labelled (CTb-IR) neurons in the dorsal, intermediate and ventral aspects of the $\mathrm{SpV}$

Numbers of retrogradely labelled (CTb-IR) neurons (also as percentages of all labelled cells found in each region)

\begin{tabular}{llrrl}
\cline { 2 - 5 } Animal & $\begin{array}{l}\text { Dorsal } \\
\text { (opthalmic) }\end{array}$ & \multicolumn{1}{l}{$\begin{array}{l}\text { Intermediate } \\
\text { (maxillary) }\end{array}$} & $\begin{array}{l}\text { Ventral } \\
\text { (mandibular) }\end{array}$ & Total \\
\hline 29 & $275(30.3 \%)$ & $291(32.0 \%)$ & $343(37.7 \%)$ & 909 \\
31 & $210(40.8 \%)$ & $156(30.3 \%)$ & $149(28.9 \%)$ & 515 \\
33 & $138(31.2 \%)$ & $88(19.9 \%)$ & $216(48.9 \%)$ & 442 \\
34 & $198(39.1 \%)$ & $172(33.9 \%)$ & $137(27.0 \%)$ & 507 \\
43 & $92(26.7 \%)$ & $76(22.0 \%)$ & $177(51.3 \%)$ & 345 \\
27 & $69(33.8 \%)$ & $38(18.6 \%)$ & $97(47.5 \%)$ & 204 \\
40 & $69(30.1 \%)$ & $48(21.0 \%)$ & $193(55.3 \%)$ & 310 \\
\hline
\end{tabular}

neurons were found in the lateral portion of the ventral horn and the lateral spinal nucleus $(<5 \%)$.

Analysis of the distribution of labelled neurons within each laminar region revealed that the greatest numbers of labelled cells in the $\mathrm{mVH}$, $\mathrm{DDH}$ and lamina $\mathrm{X}$ were located in the $\mathrm{C} 1-\mathrm{C} 4$ region (Fig. $4 \mathrm{C}$ ). However, it was interesting to note that for lamina $\mathrm{X}$ in particular, the thoraco-lumbar junction (T11-L2) and the lumbar enlargement (L3-L6) were locations of the next greatest number of labelled cells (Fig. 4C). That is, whilst lamina X contributed only around $10 \%$ of the total number of CMM projecting neurons (Fig. 4B), $40 \%$ of the labelled lamina $\mathrm{X}$ neurons were found at upper cervical spinal cord (UCC) segments and 30\% were located between T11 and L6 (Fig. 4C). Finally, as illustrated in Fig. 3, for each spinal segmental region analysed (with the exception of the sacral segmental region), the $\mathrm{mVH}$ contained always the largest number of labelled cells (41-53\%). In the sacral cord, however, the IDDH contained the greatest number of labelled cells.

\section{Spinal trigeminal nucleus (SpV)}

$\mathrm{CTb}$-IR neurons were distributed bilaterally within the $\mathrm{SpV}$, with $\sim 70 \%$ of all $\mathrm{SpV}$ labelled neurons found at the transitional region between the subnucleus caudalis (laminar) and the subnucleus interpolaris (alaminar) (see Fig. 5). Strikingly, whilst the $\mathrm{C} 1$ spinal segment was characterized by a very large number of labelled cells, it immediately rostral extension, $\mathrm{SpV}$ subnucleus caudalis, was almost devoid of CTb-IR cells (compare Figs 6 and 3). The pattern of SpV label was the same for CMM injections with and without olivary involvement (Table 2).

For the purposes of analysis, the $\mathrm{SpV}$ was divided dorsoventrally into the three regions which correspond to the terminal fields of the opthalmic, maxillary and mandibular divisions of the trigeminal nerve (Jacquin et al., 1986; Jacquin et al., 1983). There were only slight differences in the proportions of labelled neurons found within each of these regions $(33 \pm 2 \%$ dorsal; $25 \pm 2 \%$ intermediate; $42 \pm 4 \%$ ventral) (Fig. 7A, Table 2). However, there was a suggestion that: (i) the majority of CTb-IR neurons within the ventral division were caudal to those in the dorsal and intermediate divisions (Fig. 7A); and (ii) there were more labelled neurons medially $(57 \pm 2 \%)$ than laterally $(43 \pm 2 \%)$ (Fig. 7B).

\section{Nucleus of the solitary tract (NTS)}

CTb-IR neurons were located bilaterally within the nucleus of the NTS (Fig. 8), with $75 \%$ of all labelled NTS neurons found between the obex

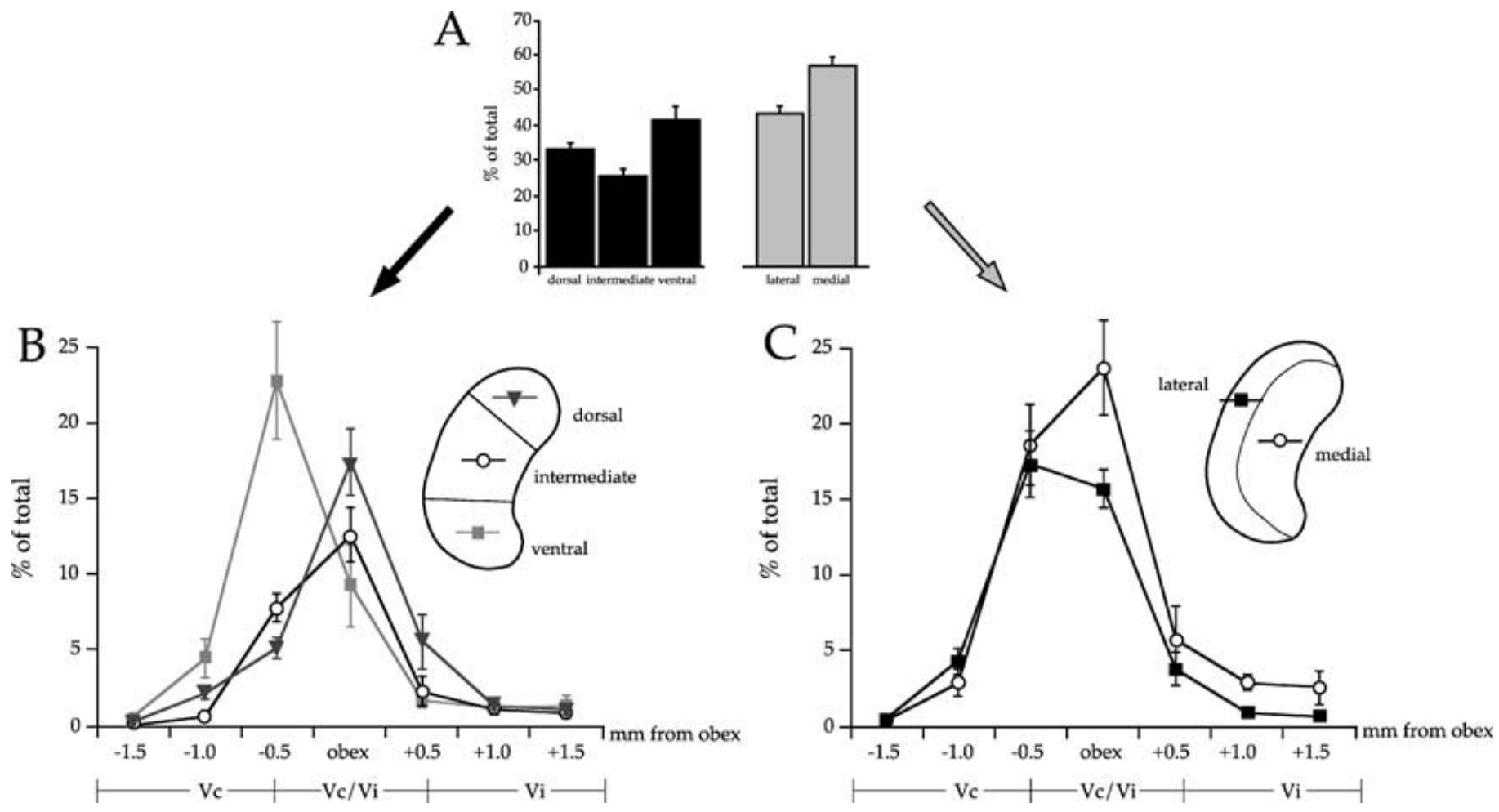

FIG. 7. (A) Histogram illustrating the distribution of retrogradely labelled neurons within the spinal nucleus of the trigeminal (SpV): (i) within the dorsal ('maxillary'), intermediate ('mandibular') and ventral ('opthalmic') regions, and (ii) within its medial and lateral aspects. The data are expressed as a percentage $( \pm$ SEM) of the total number of neurons labelled in the SpV of each animal. (B) Graph illustrating the rostro-caudal distribution (defined according to the distance from obex) of labelled neurons within the dorsal ('maxillary'), intermediate ('mandibular') and ventral ('opthalmic') regions at each of the eight medullary sections analysed. The data are expressed as a percentage $( \pm$ SEM) of the total number of neurons labelled in the SpV of each animal. (C) Graph illustrating the rostro-caudal distribution (defined according to the distance from obex) of labelled neurons within the medial and lateral SpV at each of the eight medullary sections analysed. The data are expressed as a percentage $( \pm \mathrm{SEM})$ of the total number of neurons labelled in the SpV of each animal. 


\section{A: Rostral NTS}
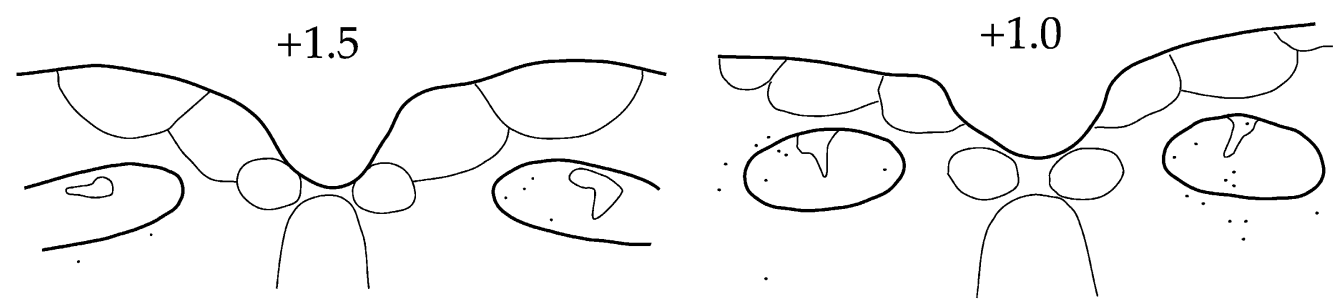

\section{B: Intermediate NTS}
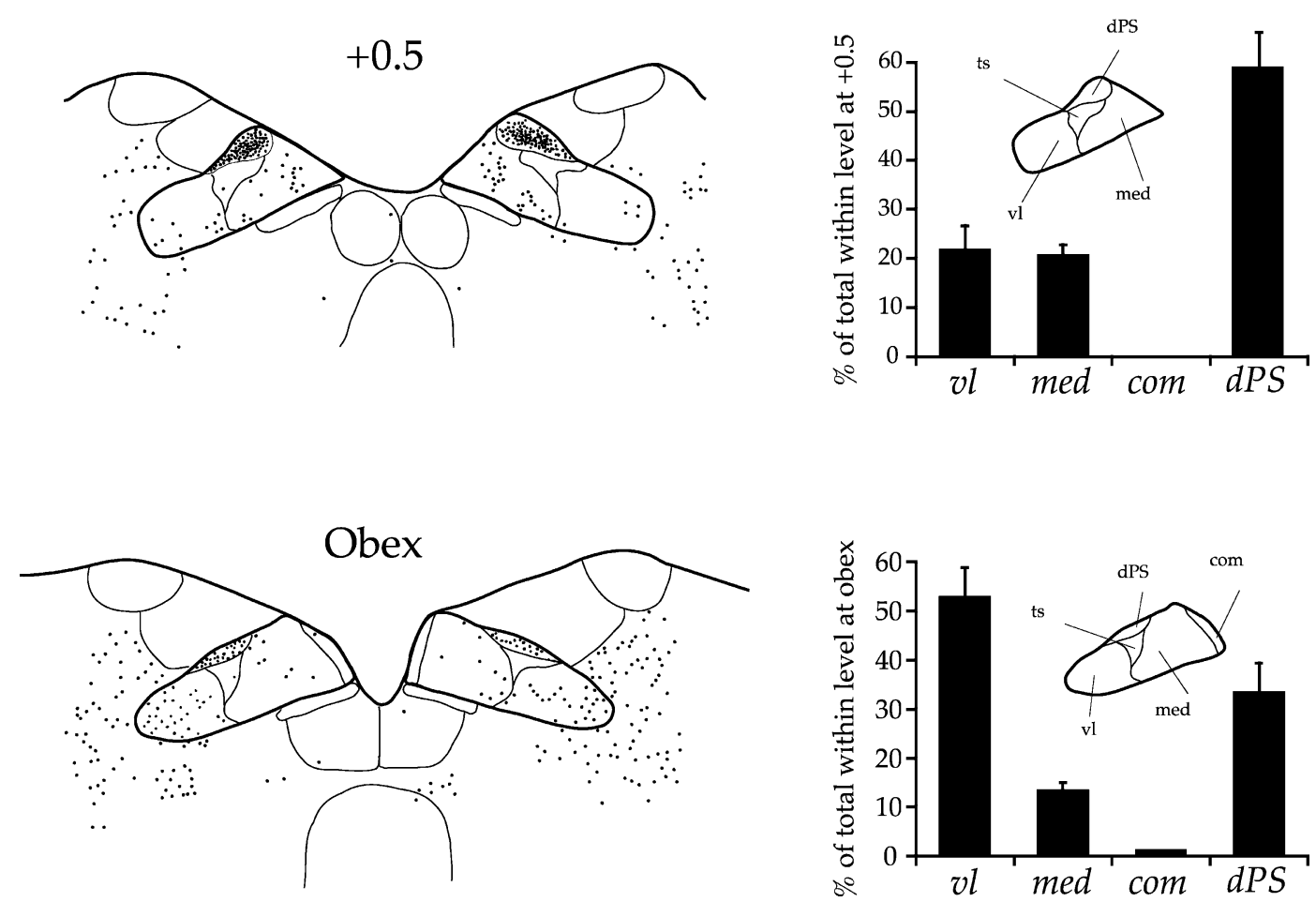

FIG. 8. Top panel, left-hand column, standard coronal sections of rostral NTS $(+1.5$ to $+1.0 \mathrm{~mm}$ rostral to obex), intermediate NTS ( $+0.5 \mathrm{~mm}$ to obex) and caudal NTS ( -0.5 to $-1.5 \mathrm{~mm}$ from obex; see part $\mathrm{C}$ on next page). The retrogradely labelled neurons from both sides of a single section $(50 \mu \mathrm{m})$ are shown as black dots (data from rat 43). Right-hand column, histograms illustrating the subnuclear distributions of retrogradely labelled neurons in the NTS. The data are expressed as a percentage $( \pm$ SEM) of the total number of neurons within that medullary rostrocaudal level for all animals analysed. The NTS sunnuclei are shown schematically along with each histogram. Note that label in dorsal column nuclei has been removed for clarity.

and the region $+0.5 \mathrm{~mm}$ (intermediate NTS) (Fig 9A and C). Labelled neurons were found predominantly within the ventrolateral and dorsal parasolitary NTS subnuclei (Figs 8, and 9B and C, and Table 3). However, it is important to note that many fewer labelled neurons were found within the dorsal parasolitary NTS subnucleus for the two CMM injections which did not infringe upon the inferior olive (Table 3: 11.5 and 28\%, without inferior olive involvement vs. 25 to $53 \%$ with olivary involvement).

Conversely the numbers of labelled neurons within the ventrolateral NTS subnucleus was greater in animals in which the CMM injections sites did not infringe upon the inferior olives (39 and 55\% without olivary involvement vs. $20-46 \%$, with olivary involvment). There was little difference in the mean numbers of labelled cells in the medial NTS (22.4\% without olivary involvement vs. $17.7 \%$, with olivary involvement). The rostral and commissural NTS subnuclei contained the fewest numbers of CTb-IR cells for all CMM injections (i.e. with or without olivary involvement; $5 \pm 1 \%$ and $4 \pm 0.5 \%$, respectively).

\section{Discussion}

The aim of the present study was to determine, using the method of the retrograde transport of $\mathrm{CTb}$, whether the vasodepressor region of the $\mathrm{CMM}$ received spinal, $\mathrm{SpV}$ or NTS inputs. The results of our experiments revealed that the vasodepressor part of the CMM receives inputs from: (i) spinal neurons of the deep dorsal horn, medial ventral horn and lamina $\mathrm{X}$ at all rostro-caudal levels of the spinal cord (however, $\sim 60 \%$ of this total spinal input to the CMM arises from upper cervical spinal segments $\mathrm{C} 1-\mathrm{C} 4$ ); (ii) $\mathrm{SpV}$ neurons, primarily at the interface of subnucleus caudalis and subnucleus interpolaris; and (iii) neurons 


\section{C: Caudal NTS}
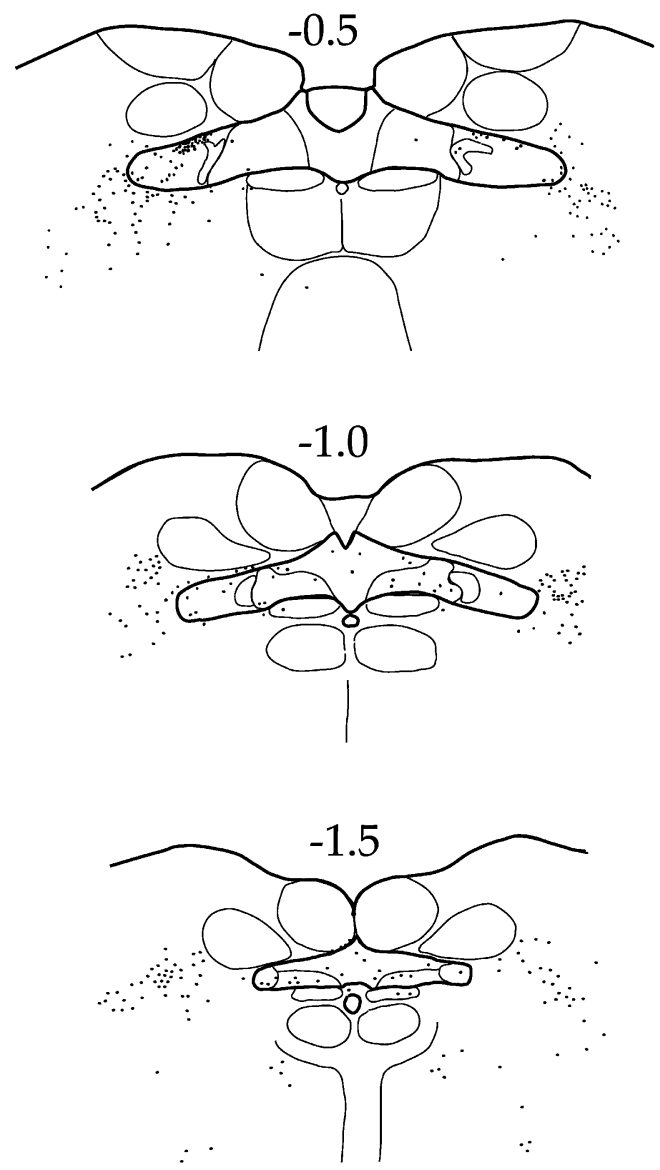

FIG. 8. continued

within the intermediate region of the NTS, specifically from the ventrolateral, medial and dorsal parasolitary subnuclei.

\section{Technical considerations}

The problem of uptake and transport by damaged fibres of passage is always a concern whatever the choice of tracer or method of injection. We attempted to minimize both the spread of tracer and damage to fibres of passage by iontophoretic application of $\mathrm{CTb}$ using micropipettes with relatively small tip diameters $(<30 \mu \mathrm{m})$. The 'vasodepressor' part of the CMM is a relatively circumscribed region; from obex to approximately $+1.5 \mathrm{~mm}$ rostral to obex, encompassing the caudal nucleus raphé obscurus and raphé pallidus, bounded dorsally by the hypoglossal nucleus, ventrolaterally by the inferior olives and medial reticular formation (Henderson et al., 1998b, 2000, 2002), and only injections in which the core of the CTb deposit was located within these boundaries were selected for analysis. Particular attention was paid to comparing CMM injections with and without inferior olivary nucleus involvement.

\section{Location of CMM-projecting spinal neurons}

The distribution of CMM-projecting spinal neurons reported here is in broad agreement with general observations that spinal projections to medial medullary structures arise primarily from the deep dorsal horn
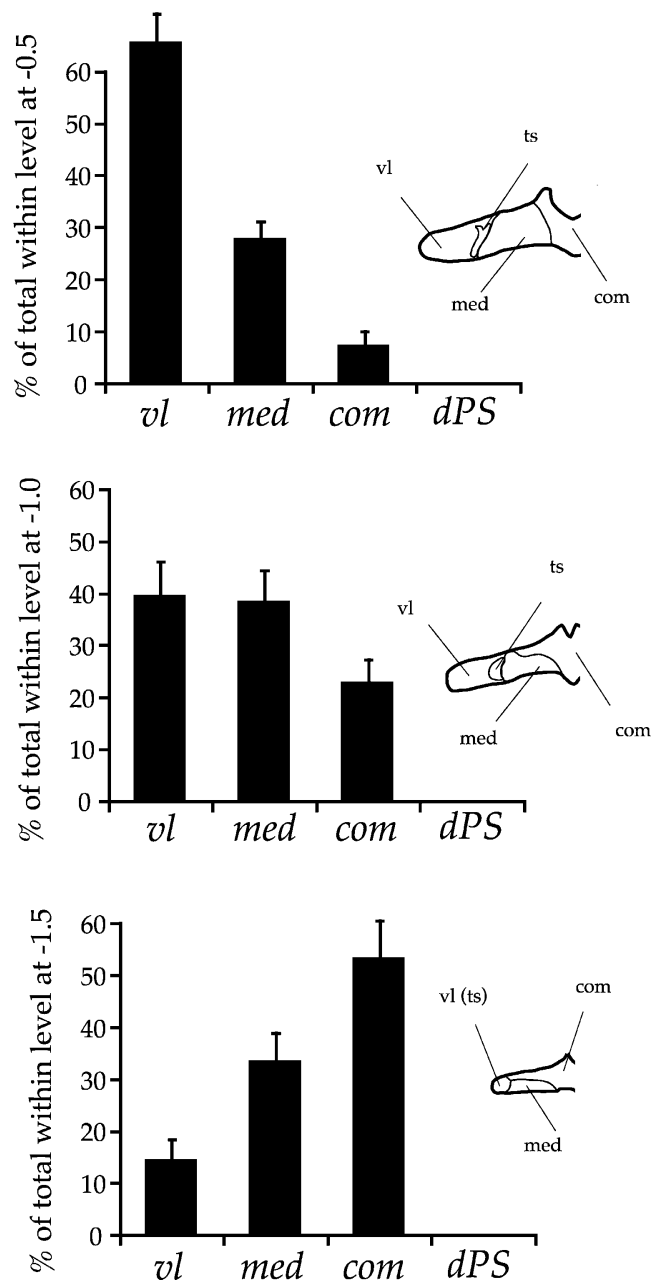

(laminae IV/V), the medial aspects of the intermediate and ventral grey (laminae VI-VIII) and lamina X (Menetrey et al., 1983; Nogueira et al., 2000). In this study, however, retrograde tracer injections were restricted to the vasodepressor part of the CMM.

As summarized in Figs 2 and 3, the UCC contained by far the greatest number of CMM-projecting neurons, with $\sim 40 \%$ of all neurons labelled in the spinal cord located within a single segment, $\mathrm{C} 1$. Those UCC laminae containing the greatest numbers of CMM-projecting neurons ( $\mathrm{mDDH}, \mathrm{IDDH}$ and $\mathrm{mVH}$ ) correspond to regions which receive primary afferents of deep neck muscles, many of which are driven by nociceptive signals (Abrahams et al., 1979, 1981, 1984a, b, 1989; Mysicka \& Zenker, 1981; Ammann et al., 1983; Pfaller \& Arvidsson, 1988; Chudler et al., 1991; Prihoda et al., 1991; Yezierski \& Broton, 1991; Yezierski \& Mendez, 1991) and propriospinal afferents arising from neurons of the SDH and LSN at thoracic and lumbar spinal levels (Craig et al., 1992; Matsushita \& Ikeda, 1973; Matsushita et al., 1979; Giesler \& Elde, 1985; Leah et al., 1988; Gonzalo \& Rotinen, 1990; Pubols \& Haring, 1995; Matsushita, 1998). This suggests that: (i) nociceptive signals arising from neck muscles; and (ii) signals arising from thoracic and abdominal viscera, or somatic structures of the hindlimb (including nociceptive/thermal inputs relayed from SDH and LSN which ascend to the UCC via propriospinal pathways) are likely sources of spinal afferent drive onto the CMM 

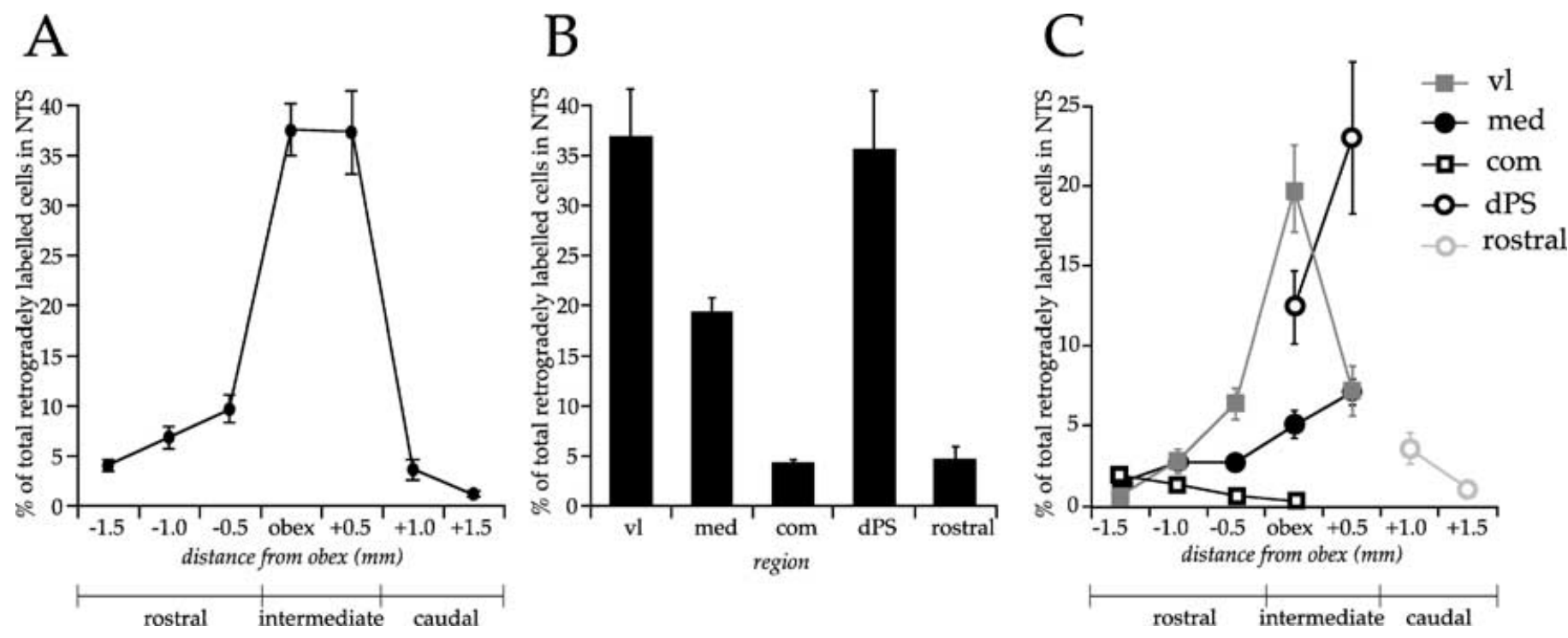

FIG. 9. (A) Graph illustrating the distribution of retrogradely labelled neurons within the nucleus of the solitary tract (NTS) at each of the seven medullary sections $(500 \mu \mathrm{m}$ apart $)$ analysed. The rostro-caudal location of the sections are defined according to distance $(\mathrm{mm})$ from obex. The data are expressed as a percentage $( \pm$ SEM) of the total number of neurons labelled in the NTS of each animal. (B) Histogram illustrating the distribution of retrogradely labelled neurons within subnuclei of NTS; vl, ventrolateral nucleus; med, medial nucleus; com, commissural nucleus; dPS, dorsal parasolitary nucleus; rostral, rostral nuclei. The data are expressed as a percentage $( \pm$ SEM) of the total number of neurons labelled in the NTS of each animal. (C) Graph illustrating the rostro-caudal distribution (defined according to the distance from obex) of labelled neurons within the ventrolateral nucleus, medial nucleus, commissural nucleus, dorsal parasolitary nucleus and rostral nuclei at each of the seven medullary sections analysed. The data are expressed as a percentage ( \pm SEM) of the total number of neurons labelled in the NTS of each animal.

'vasodepressor' region (Andrew \& Craig, 2001; Craig et al., 1994; Craig, 1996; Han et al., 1998; Craig \& Andrew, 2002).

Other than the UCC, lamina $\mathrm{X}$ at the level of thoraco-lumbar junction (T11-T12 and L3-L6) stood out as an additional region of interest (see Fig. 3). At these spinal segmental regions lamina $\mathrm{X}$ is a major site of termination of renal (T10-L2) (Knuepfer et al., 1988; Simon \& Schramm, 1984; Wyss \& Donovan, 1984; Weiss \& Chowdhury, 1998) and pelvic visceral (T10-L6) afferents (Birder et al., 1991; Morgan et al., 1981; Kuo et al., 1983; Nadelhaft \& Booth, 1984; McKenna \& Nadelhaft, 1986; Morgan et al., 1986a, b). As $~ 30 \%$ of lamina $\mathrm{X}$ neurons projecting to the CMM originate at the level of the thoraco-lumbar junction, these results indicate a possible, reasonably direct route via which renal and pelvic visceral signals could modulate the activity of CMM 'vasodepressor' neurons (see below, discussion of afferent signals triggering decompensation).

\section{Location of CMM-projecting SpV neurons}

The $\mathrm{SpV}$ transition region (i.e. junction of subnuclei caudalis and interpolaris) contains terminals of all three branches of the trigeminal nerve. As revealed by both single unit recording and immediate early gene expression ( $c$-fos) studies, neurons within the $\mathrm{SpV}$ transition region are profoundly activated by either acute or chronic noxious stimulation of superficial or deep orofacial structures (e.g. cornea, temperomandibular joint, tongue, vibrissae pad) (Bereiter et al., 1994; Hathaway et al., 1995; Meng \& Bereiter, 1996; Imbe et al., 1999; Zhou et al., 1999; Imbe et al., 2001). Our observation that the $\mathrm{SpV}$ transition region contained $\sim 70 \%$ of CMM-projecting $\mathrm{SpV}$ neurons (see Fig. 7 and Table 2) suggests that pain of orofacial origin may strongly influence the activity of CMM 'vasodepressor' neurons. In this regard it is well documented that noxious stimulation of the orofacial region can evoke a marked vasodepression (the so-called trigeminal depressor reflexes). In newborn animals such stimulation can produce a 'vaso-vagal' episode akin to the hypotension and bradycardia characteristic of the decompensatory response to haemorhage. Furthermore, it has been reported that lesion or microinjection of GABA agonists (muscimol) into the CMM blocks the hypotension (but not the bradycardia) evoked by electrical stimulation of either the Vth nerve or spinal tract of V (Clement \& McCall, 1989; McCall \& Harris, 1987).

\section{Location of CMM-projecting NTS neurons}

The major findings were that CMM-projecting NTS neurons were located predominantly in: (i) the ventrolateral subnucleus which receive vagal, but little direct spinal input, and (ii) the medial

TABLE 3. Numbers of retrogradely labelled (CTb-IR) neurons in each of the subnuclei of the solitary tract

\begin{tabular}{|c|c|c|c|c|c|c|}
\hline \multirow[b]{2}{*}{ Animal } & \multicolumn{6}{|c|}{ Numbers of retrogradely labelled (CTb-IR) neurons (also as percentages of all labelled cells found in each region) } \\
\hline & Commissural & Medial & Ventrolateral & Parasolitary & Rostral & Total \\
\hline 29 & $18(3.8 \%)$ & $86(18.4 \%)$ & $16(24.8 \%)$ & $235(50.2 \%)$ & $13(2.8 \%)$ & 368 \\
\hline 31 & $25(6.6 \%)$ & $72(18.9 \%)$ & $77(20.2 \%)$ & $203(53.3 \%)$ & $4(2.8 \%)$ & 381 \\
\hline 33 & $17(3.4 \%)$ & $94(18.5 \%)$ & $233(46.0 \%)$ & $150(29.6 \%)$ & $13(2.6 \%)$ & 507 \\
\hline 34 & $18(2.8 \%)$ & $73(11.3 \%)$ & $185(28.5 \%)$ & $322(49.7 \%)$ & $50(7.7 \%)$ & 648 \\
\hline 43 & $10(4.4 \%)$ & $49(21.6 \%)$ & $100(44.1 \%)$ & $57(25.1 \%)$ & $11(4.8 \%)$ & 227 \\
\hline 27 & $11(4.3 \%)$ & $66(25.9 \%)$ & $99(38.8 \%)$ & $72(28.2 \%)$ & $7(2.7 \%)$ & 255 \\
\hline 40 & $13(3.7 \%)$ & $66(21.6 \%)$ & $193(55.3 \%)$ & $40(11.5 \%)$ & $37(10.6 \%)$ & 349 \\
\hline
\end{tabular}


subnuclus, which in addition to vagal input, receives significant spinal input from laminae I, IV/V and X (Menetrey \& Basbaum, 1987). The projection to the CMM arising from the dorsal parasolitary subnucleus appears to target predominantly the inferior olive (see Table 3), specifically the medial accessory nucleus (Barmack et al., 1998).

As discussed in the Introduction, earlier findings indicate that cardiovascular reflexes triggered by activation of high pressure baroreceptor afferents or $5-\mathrm{HT}_{3}$ sensitive cardio-pulmonary vagal afferents, or hypotension and bradycardia evoked by electrical stimulation of the vagus, are not altered by either lesion or neural blockade of the CMM vasodepressor region (Johansson, 1962; Coleman \& Dampney, 1998; Henderson et al., 2000). Thus it may seem surprising that vagalrecipient NTS subnuclei have strong projections to the CMM. In this regard, it is important to remember that the CMM 'vasodepressor' region includes populations of neurons known to play important roles in gastrointestinal functions and respiratory regulation (Garrick et al., 1994; Holtman et al., 1986a, b; Lalley, 1986a, b; McCown et al., 1986; Millhorn, 1986; Yen \& Hwang, 1989; Morin et al., 1990a, b; Yang et al., 1990; Garrick et al., 1992; Yang et al., 1992; Tache et al., 1993; Kaneko et al., 1995; Taché et al., 1995). In particular, anatomical and electrophysiological evidence indicate that vagal afferent fibres carrying signals from lung stretch receptors terminate and influence the activity of ventrolateral NTS neurons (including those of the dorsal respiratory group) (Bellingham \& Lipski, 1992; Kalia \& Sullivan, 1982). Such signals are an important afferent drive likely relayed via the NTS-CMM projection identified here.

\section{Afferents triggering phase II/decompensatory response}

As stated in the Introduction the integrity of the CMM 'vasodepressor region' is critical for the expression of the decompensatory/phase II response to progressive blood loss (Henderson et al., 2000; Henderson et al., 2002; Heslop et al., 2002), as well as the hypotension and bradycardia triggered by pain of deep origin (muscle) (Johansson, 1962). The aim of this study was to establish if the CMM vasodepressor region received direct spinal, $\mathrm{SpV}$, and/or NTS projections, likely to relay somatic and visceral signals initiating decompensation. Our anatomical findings indicate that the vasodepressor part of the $\mathrm{CMM}$ receives afferents from spinal, $\mathrm{SpV}$ and NTS regions each of which receives somatic and visceral afferents, which are likely candidates to trigger components of the phase II/decompensatory response to haemorrhage. Specifically our data suggest the following: (i) vagal afferents (non-5HT3-sensitive) to CMM-projecting NTS neurons are still candidates to trigger the bradycardia, decrease in cardiac contractility and renal sympathoinhibition which are characteristic of a phase II/decompensatory response to haemorrhage; (ii) nociceptive spinal afferents to CMM projecting neurons are candidates to drive the vasodepressor response characteristic of pain of deep origin (e.g. muscle), as well as the phase II/decompensatory response to haemorrhage; and (iii) nociceptive afferents to CMM-projecting SpV ('transition region') neurons are candidates to drive the hypotensive component of trigeminal depressor reflexes

\section{Acknowledgements}

This research was supported by Australian NHMRC grants (970688 and 211142).

\section{Abbreviations}

$\mathrm{CMM}$, caudal midline medulla; $\mathrm{CTb}$, cholera toxin $\beta$-subunit; $\mathrm{DAB}$, diaminobenzadine; IR, immunoreactivity; IDDH, lateral deep dorsal horn;
LSN, lateral spinal nucleus; IVH, lateral ventral horn; $\mathrm{mDDH}$, medial deep dorsal horn; $\mathrm{mVH}$, medial ventral horn; NTS, nucleus of the solitary tract; PB, phosphate buffer; $\mathrm{PBH}$, phosphate buffered horse serum; SpV, spinal trigeminal nucleus; SDH, superficial dorsal horn; UCC, upper cervical spinal cord; vlPAG, ventrolateral column of the periaqueductal grey.

\section{References}

Abrahams, V.C. (1981) Sensory and motor specialization in some muscles of the neck. Trends Neurosci., 5, 24-27.

Abrahams, V.C. (1989) The distribution of muscle and cutaneous projections to the dorsal horn of the upper cervical spinal cord of the cat. In Cervero, F., Bennet, G.J. \& Headly, P.M. (eds), Processing of Sensory Information in the Superficial Dorsal Horn. Plenum, New York, pp. 41-56.

Abrahams, V.C., Anstee, G., Richmond, F.J.R. \& Rose, P.K. (1979) Neck muscle and trigeminal input to the upper cervical cord and lower medulla in the cat. Can. J. Physiol. Pharmacol., 57, 842-851.

Abrahams, V.C., Lynn, B. \& Richmond, F.J.R. (1984a) Organization and sensory properties of small myelinated fibres in the dorsal cervical rami of the cat. J. Physiol. (Lond.)., 347, 177-187.

Abrahams, V.C., Richmond, F.J. \& Keane, J. (1984b) Projections from C2 and C3 nerves supplying muscles and skin of the cat neck: a study using transganglionic transport of horseradish peroxidase. J. Comp. Neurol., 230, 142-154.

Almada, G.L., Pires, J.G., Dantas, M.A. \& Futuro-Neto, H.A. (1997) Pressor effects elicited by stimulation within the medullary raphe nuclei of the guinea pig (Cavia porcellus). Acta Physiol., Pharmacol. Therap. Latinoamericana., 47, 229-236.

Ammann, B., Gottschall, J. \& Zenker, W. (1983) Afferent projections from rat longus capitus muscle studied by transganglionic transport of HRP. Anat. Embryol., 166, 275-289.

Andrew, D. \& Craig, A.D. (2001) Spinothalamic lamina I neurones selectively responsive to cutaneous warming in cats. J. Physiol. (Lond.), 537, 489-495.

Barmack, N.H., Fredette, B.J. \& Mugnaini, E. (1998) Parasolitary nucleus: a source of GABAergic vestibular information to the inferior olive of rat and rabbit. J. Comp. Neurol., 392, 352-372.

Bellingham, M.C. \& Lipski, J. (1992) Morphology and electrophysiology of superior laryngeal nerve afferents and postsynaptic neurons in the medulla oblongata of the cat. Neuroscience, 48, 205-216.

Bereiter, D.A., Hathaway, C.B. \& Benetti, A.P. (1994) Caudal portions of the spinal trigeminal complex are necessary for autonomic responses and display Fos-like immunoreactivity after corneal stimulation in the cat. Brain Res., 657, 73-82.

Birder, L.A., Roppolo, J.R., Iadarola, M.J. \& de Groat, W.C. (1991) Electrical stimulation of visceral afferent pathways in the pelvic nerve increases c-fos in the rat lumbosacral spinal cord. Neurosci. Letts., 129, 193-196.

Cavun, S. \& Millington, W.R. (2001) Evidence that hemorrhagic hypotension is mediated by the ventrolateral periaqueductal gray region. Am. J. Physiol. Reg. Integ. Comp. Physiol., 281, R747-R752.

Cavun, S., Resch, G.E., Evec, A.D., Rapacon-Baker, M.M. \& Millington, W.R. (2001) Blockade of delta opioid receptors in the ventrolateral periaqueductal gray region inhibits the fall in arterial pressure evoked by hemorrhage. J. Pharmacol. Exp. Therap., 297, 612-619.

Chudler, E.H., Foote, W. \& e. \& Poletti, C.E. (1991) Responses of cat C1 spinal dorsal and ventral horn neurons to noxious and non-noxious stimulation of the head and face. Brain Res., 555, 181-192.

Clement, C.I., Keay, K.A., Owler, B.K. \& Bandler, R. (1996) Common patterns of increased and decreased Fos expression in midbrain and pons evoked by noxious deep somatic and noxious visceral manipulations in the rat. J. Comp. Neurol., 366, 495-515.

Clement, C.I., Keay, K.A., Podzbenko, K., Gordon, B.D. \& Bandler, R. (2000) Spinal sources of noxious visceral and noxious deep somatic afferent drive onto ventrolateral periaqueductal gray of the rat. J. Comp Neurol., 425, 323-344.

Clement, M.E. \& McCall, R.B. (1989) Characterization of midline medulla role in the trigeminal depressor response. Am. J. Physiol., 256, R1111-R1120.

Coleman, M.J. \& Dampney, R.A. (1995) Powerful depressor and sympathoinhibitory effects evoked from neurons in the caudal raphe pallidus and obscurus. Am. J. Physiol., 268, R1295-R1302.

Coleman, M.J. \& Dampney, R.A. (1998) Sympathoinhibition evoked from caudal midline medulla is mediated by GABA receptors in rostral VLM. Am. J. Physiol., 274, R318-R323. 
Craig, A.D. (1996) An ascending general homeostatic afferent pathway originating in lamina I. Prog. Brain Res., 107, 225-242.

Craig, A.D. \& Andrew, D. (2002) Responses of spinothalamic lamina I neurons to repeated brief contact heat stimulation in the cat. J. Neurophysiol., 87, 1902-1914

Craig, A.D., Broman, J. \& Blomqvist, A. (1992) Lamina I spinocervical tract terminations in the medial part of the lateral cervical nucleus in the cat. J. Comp. Neurol., 322, 99-110.

Craig, A.D., Bushnell, M.C., Zhang, E.T. \& Blomqvist, A. (1994) A thalamic nucleus specific for pain and temperature sensation. Nature, 372, 770-773.

D’Amico, M., Berrino, L., Pizzirusso, A., de Novellis, V. \& Rossi, F. (1996) Opposing effects on blood pressure following the activation of metabotropic and ionotropic glutamate receptors in raphe obscurus in the anaesthetized rat. Naunyn-Schmiedebergs Arch. Pharmacol., 353, 302-305.

Evans, R.G. \& Ludbrook, J. (1991) Chemosensitive cardiopulmonary afferents and the haemodynamic response to simulated haemorrhage in conscious rabbits. Br. J. Pharmacol., 102, 533-539.

Evans, R.G., Ludbrook, J. \& and. Ventura (1994) Role of vagal afferents in the haemodynamic response to acute central hypovolaemia in unanaesthetised rabbits. J. Auton. Nerv. Syst., 46, 251-260.

Faria, M.G.C., Dantas, M.A. \& Futuro-Neto, H.A. (1996) Pressor effects elicited by stimulation within the medullary raphe nuclei of the golden hamster (Mesocricetus auratus). Braz. J. Med. Biol. Res., 29, 533-540.

Fitzpatrick, A.P., Banner, N., Cheng, A., Yacoub, M. \& Sutton, R. (1993) Vasovagal rections may occur after orthotopic heart transplantation. J. Am. Coll. Cardiol., 21, 1132-1137.

Garrick, T., Prince, M., Yang, H., Ohning, G. \& Tache, Y. (1994) Raphe pallidus stimulation increases gastric contractility via TRH projections to the dorsal vagal complex in rats. Brain Res., 636, 343-347.

Garrick, T., Yang, H., Trauner, M., Livingston, E. \& Tache, Y. (1992) Thyrotropin-releasing hormone analog injected into the raphe pallidus and obscurus increases gastric contractility in rats. Eur J. Pharmacol., 223, 75-81.

Giesler, G.J. Jr \& Elde, R.P. (1985) Immunocytochemical studies of the peptidergic content of fibers and terminals within the lateral spinal and lateral cervical nuclei. J. Neurosci., 5, 1833-1841.

Gilbey, M., Coote, J.H., Macleod, V.H. \& Peterson, D.F. (1981) Inhibition of sympathetic activity by stimulating in the raphe nuclei and the role of 5-hydroxytryptamine in this effect. Brain Res., 226, 131-142.

Gonzalo, L.M. \& Rotinen, S. (1990) Ascending projections to the first two myelomeres. J. Hirnforsch., 31, 223-226.

Han, Z.S., Zhang, E.T. \& Craig, A.D. (1998) Nociceptive and thermoreceptive lamina I neurons are anatomically distinct. [see comments.]. Nature Neurosci., 1, 218-225.

Hathaway, C.B., Hu, J.W. \& Bereiter, D.A. (1995) Distribution of Fos-like immunoreactivity in the caudal brainstem of the rat following noxious chemical stimulation of the temporomandibular joint. J. Comp. Neurol., 356, 444- 456.

Henderson, L.A., Keay, K.A. \& Bandler, R. (1998a) Hypotension following acute hypovolaemia depends on the caudal midline medulla. Neuroreport, 9 , 1839-1844.

Henderson, L.A., Keay, K.A. \& Bandler, R. (1998b) The ventrolateral periaqueductal gray projects to caudal brainstem depressor regions: a functionalanatomical and physiological study. Neuroscience, 82, 201-221.

Henderson, L.A., Keay, K.A. \& Bandler, R. (2000) Caudal midline medulla mediates behaviourally-coupled but not baroreceptor-mediated vasodepression. Neuroscience, $\mathbf{9 8}, 779-792$.

Henderson, L.A., Keay, K.A. \& Bandler, R. (2002) Delta- and kappa-opioid receptors in the caudal midline medulla mediate haemorrhage-evoked hypotension. Neuroreport, 13, 729-733.

Herbert, H., Moga, M.M. \& Saper, C.B. (1990) Connections of the parabrachial nucleus with the nucleus of the solitary tract and the medullary reticular formation in the rat. J. Comp. Neurol., 293, 540-580.

Herbert, H. \& Saper, C.B. (1992) Organization of medullary adrenergic and noradrenergic projections to the periaqueductal gray matter in the rat. J. Comp. Neurol., 315, 34-52.

Heslop, D.J., Keay, K.A. \& Bandler, R. (2002) Haemorrhage-evoked compensation and decompensation are mediated by distinct caudal midline medullary regions in the urethane-anaesthetised rat. Neuroscience, 113, 555-567.

Holtman, J.R. Jr, Anastasi, N.C., Norman, W.P. \& Dretchen, K.L. (1986a) Effect of electrical and chemical stimulation of the raphe obscurus on phrenic nerve activity in the cat. Brain Res., 362, 214-220.

Holtman, J.R. Jr, Dick, T.E. \& Berger, A.J. (1986b) Involvement of serotonin in the excitation of phrenic motoneurons evoked by stimulation of the raphe obscurus. J. Neurosci., 6, 1185-1193.
Imbe, H., Dubner, R. \& Ren, K. (1999) Masseteric inflammation-induced Fos protein expression in the trigeminal interpolaris/caudalis transition zone: contribution of somatosensory-vagal-adrenal integration. Brain Res., 845 , $165-175$.

Imbe, H., Iwata, K., Zhou, Q.Q., Zou, S., Dubner, R. \& Ren, K. (2001) Orofacial deep and cutaneous tissue inflammation and trigeminal neuronal activation. Implications for persistent temporomandibular pain. Cells Tissues Organs, 169, 238-247.

Ip, J.C.Y., Bandler, R. \& Keay, K.A. (2002) Bilateral inactivation of the ventrolateral column of the the PAG blocks haemorrhage evoked hypotension in the rat. Proc. Aust. Neurosci. Soc., 13, 116.

Jacquin, M.F., Renehan, W.E., Mooney, R.D. \& Rhoades, R.W. (1986) Structure-function relationships in rat medullary and cervical dorsal horns. I. Trigeminal primary afferents. J. Neurophysiol., 55, 1153-1186.

Jacquin, M.F., Semba, K., Egger, M.D. \& Rhoades, R.W. (1983) Organization of HRP-labeled trigeminal mandibular primary afferent neurons in the rat. J. Comp. Neurol., 215, 397-420.

Johansson, B. (1962) Circulatory responses to stimulation of somatic afferents. Acta Physiol. Scand., 57, 1-91.

Kalia, M. \& Sullivan, J.M. (1982) Brainstem projections of sensory and motor components of the vagus nerve in the rat. J. Comp. Neurol., 211, $248-265$.

Kaneko, H., Yang, H., Ohning, G. \& Tache, Y. (1995) Medullary TRH is involved in gastric protection induced by low dose of kainic acid into the raphe pallidus. Am. J. Physiol., 268, G548-G552.

Keay, K.A. \& Bandler, R. (1993) Deep and superficial noxious stimulation increases Fos like immunoreactivity in different regions of the midbrain periaqueductal gray of the rat. Neurosci. Letts., 154, 143-158.

Keay, K.A. \& Bandler, R. (1998) Vascular head pain selectively activates ventrolateral periaqueductal gray in the cat. Neurosci. Letts., 245, 58-60.

Keay, K.A., Clement, C.I., Matar, W.M., Heslop, D.J., Henderson, L.A. \& Bandler, R. (2002) Noxious activation of spinal or vagal afferents evokes distinct patterns of Fos-like immunoreactivity in the ventrolateral periaqueductal gray of unanaesthetised rats. Brain Res., 948, 122-130.

Keay, K.A., Clement, C.I., Owler, B.K., Depaulis, A. \& Bandler, R. (1994) Convergence of deep somatic and visceral nociceptive information onto a discrete ventrolateral midbrain periaqueductal gray region. Neuroscience, 61 , 727-732.

Keay, K.A., Feil, K., Gordon, B.D., Herbert, H. \& Bandler, R. (1997) Spinal afferents to functionally distinct PAG columns in the rat: An anterograde and retrograde tracing study. J. Comp. Neurol., 385, 207-229.

Knuepfer, M.M., Akeyson, E.W. \& Schramm, L.P. (1988) Spinal projections of renal afferent nerves in the rat. Brain Res., 446, 17-25.

Kuo, D.C., Nadelhaft, I., Hisamitsu, T. \& de Groat, W.C. (1983) Segmental distribution and central projections of renal afferent fibers in the cat studied by transganglionic transport of horseradish peroxidase. J. Comp. Neurol., 216, $162-174$

Lalley, P.M. (1986a) Responses of phrenic motoneurones of the cat to stimulation of medullary raphe nuclei. J. Physiol. (Lond.), 380, 349-371.

Lalley, P.M. (1986b) Serotoninergic and non-serotoninergic responses of phrenic motoneurones to raphe stimulation in the cat. J. Physiol. (Lond.), 380, 373-385.

Leah, J., Menetrey, D. \& de Pommery, J. (1988) Neuropeptides in long ascending spinal tract cells in the rat: evidence for parallel processing of ascending information. Neuroscience, 24, 195-207.

Ludbrook, J. (1993) Haemorrhage and shock. In Hainsworth, R., \& \&.Mark, A. (eds.), Cardiovascular Reflex Control in Health and Disease. Saunders, London, pp. 463-490.

Matsushita, M. (1998) Ascending propriospinal afferents to area X (substantia grisea centralis) of the spinal cord in the rat. Exp. Brain Res., 119, 356-366.

Matsushita, M. \& Ikeda, M. (1973) Propriospinal fiber connections of the cervical motor nuclei in the cat: a light and electron microscope study. J. Comp. Neurol., 150, 1-32.

Matsushita, M., Ikeda, M. \& Hosoya, Y. (1979) The location of spinal neurons with long descending axons (long descending propriospinal tract neurons) in the cat: a study with the horseradish peroxidase technique. J. Comp. Neurol., 184, 63-80.

McCall, R.B. \& Harris, L.T. (1987) Sympathetic alterations after midline medullary raphe lesions. Am. J. Physiol. Reg. Integ. Comp. Physiol., 253 , R91-R100.

McCown, T.J., Hedner, J.A., Towle, A.C., Breese, G.R. \& Mueller, R.A. (1986) Brainstem localization of a thyrotropin-releasing hormone-induced change in respiratory function. Brain Res., 373, 189-196.

McKenna, K.E. \& Nadelhaft, I. (1986) The organization of the pudendal nerve in the male and female rat. J. Comp. Neurol., 248, 532-549. 
Menetrey, D. \& Basbaum, A.I. (1987) Spinal and trigeminal projections to the nucleus of the solitary tract: a possible substrate for somatovisceral and viscerovisceral reflex activation. J. Comp. Neurol., 255, 439-450.

Menetrey, D., Roudier, F. \& Besson, J.M. (1983) Spinal neurons reaching the lateral reticular nucleus as studied in the rat by retrograde transport of horseradish perioxidase. J. Comp. Neurol., 220, 439-452.

Meng, I.D. \& Bereiter, D.A. (1996) Differential distribution of Fos-like immunoreactivity in the spinal trigeminal nucleus after noxious and innocuous thermal and chemical stimulation of rat cornea. Neuroscience, 72, 243-254.

Millhorn, D.E. (1986) Stimulation of raphe (obscurus) nucleus causes longterm potentiation of phrenic nerve activity in cat. J. Physiol. (Lond.), 381, $169-179$.

Minson, J.B., Chalmers, J.P., Caon, A.C. \& Renaud, B. (1987) Separate areas of rat medulla oblongata with populations of serotonin- and adrenaline-containing neurons alter blood pressure after 1-glutamate stimulation. J. Auton. Nerv. Syst., 19, 1939-1950.

Molander, C. \& Grant, G. (1995) Spinal cord cytoarchitecture. In Paxinos, G. (ed.), The Rat Nervous System. Academic Press, San Diego, pp. 39-45.

Morgan, C., Nadelhaft, I. \& de Groat, W.C. (1981) The distribution of visceral primary afferents from the pelvic nerve to Lissauer's tract and the spinal gray matter and its relationship to the sacral parasympathetic nucleus. J. Comp. Neurol., 201, 415-440.

Morgan, C., deGroat, W.C. \& Nadelhaft, I. (1986a) The spinal distribution of sympathetic preganglionic and visceral primary afferent neurons that send axons into the hypogastric nerves of the cat. J. Comp. Neurol., 243, 23-40.

Morgan, C., Nadelhaft, I. \& deGroat, W.C. (1986b) The distribution within the spinal cord of visceral primary afferent axons carried by the lumbar colonic nerve of the cat. Brain Res., 398, 11-17.

Morin, D., Hennequin, S., Monteau, R. \& Hilaire, G. (1990a) Depressant effect of raphe stimulation on inspiratory activity of the hypoglossal nerve: in vitro study in the newborn rat. Neurosci. Letts., 116, 299-303.

Morin, D., Hennequin, S., Monteau, R. \& Hilaire, G. (1990b) Serotonergic influences on central respiratory activity: an in vitro study in the newborn rat. Brain Res., 535, 281-287.

Morrison, S. (1993) Raphe pallidus excites a unique class of sympathetic preganglionic neurons. Am. J. Physiol. Reg. Integ Comp. Physiol., 265, R82-R89.

Mysicka, A. \& Zenker, W. (1981) Central projections of muscle afferents from the sternomastoid nerve in the rat. Brain Res., 211, 257-265.

Nadelhaft, I. \& Booth, A.M. (1984) The location and morphology of preganglionic neurons and the distribution of visceral afferents from the rat pelvic nerve: a horseradish peroxidase study. J. Comp. Neurol., 226, 238-245.

Nogueira, M.I., Rezende, B.D.D., doVale, L.E. \& Bittencourt, J.C. (2000) Afferent connections of the caudal raphe pallidus nucleus in rats: a study using the fluorescent retrograde tracers fluorogold and true blue. Anat. Anzeiger., 182, 35-45.

Oberg, B. \& Thoren, P. (1970) Increased activity in vagal cardiac afferents correlated to the appearance of reflex bradycardia during severe hemorrhage in cats. Acta Physiol. Scand., 80, 22A-23A.

Oberg, B. \& Thoren, P. (1972) Increased activity in left ventricular receptors during hemorrhage or occlusion of caval veins in the cat. A possible cause of the vaso-vagal reaction. Acta Physiol. Scand., 85, 164-173.
Oberg, B. \& Thoren, P. (1973) Circulatory responses to stimulation of left ventricular receptors in the cat. Acta Physiol. Scand., 88, 8-22.

Pfaller, K. \& Arvidsson, J. (1988) Central distribution of trigeminal and upper cervical afferents in the rat studied by anterograde transport of horseradish peroxidase conjugated to wheat germ agglutinin. J. Comp. Neurol., 268, 91-108.

Pilowsky, P.M., Kapoor, V., Minson, J.B., West, M.J. \& Chalmers, J.P. (1986) Spinal cord serotonin release and raised blood pressure after brainstem kainic acid injection. Brain Res., 366, 354-357.

Prihoda, M., Hiller, M.-S. \& Mayr, R. (1991) Central projections of cervical primary afferent fibres in the guinea pig: An HRP and WGA-HRP tracer study. J. Comp. Neurol., 308, 418-431.

Pubols, B.H. Jr \& Haring, J.H. (1995) The raccoon spinocervical and spinothalamic tracts: a horseradish peroxidase study. Brain Res. Rev., 20, 196-208.

Schadt, J.C. \& Ludbrook, J. (1991) Hemodynamic and neurohumoral responses to acute hypovolemia in conscious mammals. Am. J. Physiol., 260, H305-H318.

Simon, O.R. \& Schramm, L.P. (1984) The spinal course and medullary termination of myelinated renal afferents in the rat. Brain Res., 290, 239-247.

Taché, Y., Yang, H. \& Kaneko, H. (1995) Caudal raphe - dorsal vagal complex peptidergic projections: role in gastric vagal control. Peptides, 16, 431-435.

Tache, Y., Yang, H. \& Yoneda, M. (1993) Vagal regulation of gastric function involves thyrotropin-releasing hormone in the medullary raphe nuclei and dorsal vagal complex. Digestion, 54, 65-72.

Verberne, A.J., Sartor, D.M. \& Berke, A. (1999) Midline medullary depressor responses are mediated by inhibition of RVLM sympathoexcitatory neurons in rats. Am. J. Physiol., 276, R1054-R1062.

Weiss, M.L. \& Chowdhury, S.I. (1998) The renal afferent pathways in the rat: a pseudorabies virus study. Brain Res., 812, 227-241.

Wyss, J.M. \& Donovan, M.K. (1984) A direct projection from the kidney to the brainstem. Brain Res., 298, 130-134.

Yang, H., Ishikawa, T. \& Tache, Y. (1990) Microinjection of TRH analogs into the raphe pallidus stimulates gastric acid secretion in the rat. Brain Res., 531, $280-285$.

Yang, H., Stephens, R.L. \& Tache, Y. (1992) TRH analogue microinjected into specific medullary nuclei stimulates gastric serotonin secretion in rats. Am. J. Physiol., 262, G216-G222.

Yen, C.T. \& Hwang, J.C. (1989) Control of phrenic nerve activity and blood pressure by the medullary raphe nuclei in cats. Proc. Natl Sci. Council Repub. China, 13, 89-96.

Yen, C.T., Hwang, J.C., Su, C.K., Lin, Y.F., Yang, J.M. \& Chai, C.Y. (1991) Differential actions of the medial region of caudal medulla on autonomic nerve activities. Clin. Exp. Pharmacol. Physiol., 18, 743-751.

Yezierski, R.P. \& Broton, J.G. (1991) Functional properties of spinomesencephalic cells in the upper cervical spinal cord of the cat. Pain, 45, 187-198.

Yezierski, R.P. \& Mendez, C.M. (1991) Spinal distribution and collateral projections of rat spinomesencephalic tract cells. Neuroscience, 44, 113-130.

Zhou, Q., Imbe, H., Dubner, R. \& Ren, K. (1999) Persistent Fos protein expression after orofacial deep or cutaneous tissue inflammation in rats: implications for persistent orofacial pain. J. Comp. Neurol., 412, 276-291. 